\title{
The Millennium Scientific Meeting, Manchester, 9-11 October 2000 (Hosted by the Faculty of Accident and Emergency Medicine)
}

\author{
EMRS/SSL International plc \\ Prize Session
}

Use of plasma DNA analysis to derive early prediction rules for post-traumatic organ failure

T H RAINER, Y M D LO, L Y S CHAN, P K W LAM, E K WONG, N M HJELM, R A COCKS

Accident and Emergency Medicine Academic Unit and Department of Chemical Pathology, The Chinese University of Hong Kong and Prince of Wales Hospital, Hong Kong

Background - The discovery of effective treatments preventing or mimising post-traumatic complications may be hampered by our inability to target high risk patients early after injury. The purpose of this study was to derive a guideline for the prediction of posttraumatic organ failure using cell free (plasma) DNA and other predictors of post-traumatic complications.

Methods - The research ethics committee approved a prospective, observational study investigating molecular responses of patients to injury. Plasma DNA was measured using a real time, quantitative, polymerase chain reaction assay for the $\beta$ globin gene in 84 patients (mean age 38 (SD 16) years; $83 \%$ male) triaged to an emergency department resuscitation room within a median time of 60 minutes (interquartile range 50, 90; range 30-240) from injury. Other variables were injury severity scores, white cell count (WCC) and shock index (SI). Organ failure (OF) and multiple organ dysfunction syndrome (MODS) occurred in 21 of $84(25 \%)$ and 9 of $84(11 \%)$ cases respectively. After univariate and receiver operator curve analysis, data were further analysed using a classification and regression tree.

Results-Within four hours of injury, OF could be correctly predicted (predictive value positive, $\mathrm{PV}+$ ) in $85.7 \%$ cases ( $\mathrm{n}=18$ of 21 ; $95 \%$ CI $62.6 \%$ to $96.2 \%$ ) by: (1) cell free DNA > 140000 genome equivalents/ml, (2) injury severity score (ISS) $>27$ and (3) WCC $>13.4\left(\times 10^{9} / 1\right)$. OF could be correctly excluded (predictive value negative, $\mathrm{PV}-$ ) in $95.2 \%$ cases $(\mathrm{n}=60$ of $63 ; 95 \% \mathrm{CI} 85.8 \%$ to $98.8 \%$ ) by (1) cell free DNA $\leqslant 141000$ genome equivalents $/ \mathrm{ml}$, (2) ISS $\leqslant 27$ and (3) WCC $\leqslant 13.4$. Sensitivity and specificity were $85.7 \%(95 \%$ CI, $62.6 \%$ to $96.2 \%$ ) and $95.2 \%$ (95\% CI, $85.8 \%$ to $98.8 \%)$ respectively. MODS could be correctly predicted (PV+) in $87.5 \%$ cases $(\mathrm{n}=7$ of $8 ; 95 \% \mathrm{CI} 46.7 \%$ to 99.3\%) by: (1) cell free DNA > 108000 copies $/ \mathrm{ml}$, (2) maximal abbreviated injury score (MAIS) $>3$, and (3) SI > 0.72. MODS could be correctly excluded (PV-) in $97.3 \%$ cases ( $\mathrm{n}=71$ of $73 ; 95 \% \mathrm{CI} 89.6 \%$ to $99.5 \%$ ) by (1) cell free DNA $\leqslant 108000$ copies/ml, (2) MAIS $\leqslant 3.0$ and (3) SI $\leqslant 0.72$. Sensitivity and specificity were $77.8 \%$ (95\% CI, $40.2 \%$ to $96.1 \%)$ and $98.6 \%(95 \% \mathrm{CI}, 91.5 \%$ to $99.9 \%)$ respectively.

Conclusion-Plasma DNA analysis allows the development of early accurate guidelines for the prediction of post-traumatic $\mathrm{OF}$ and MODS. These guidelines now require prospective validation.

The effects of in vivo haemodilution with $0.9 \%$ sodium chloride and Gelofusine on whole blood coagulation and platelet function

E V BRAZIL ${ }^{\star}, \mathrm{U} \mathrm{SHAH}^{\star \star}, \mathrm{M} \mathrm{MACEY}^{\star \star}$, T J COATS ${ }^{\star}$ ${ }^{\star}$ Academic Unit, Accident and Emergency Department, and ${ }^{\star *}$ Department of Haematology, Royal London Hospital, Whitechapel, London, E1 $1 B B$

Introduction-In vitro haemodilution with Gelofusine reduces clot quality in contrast with saline, which has a procoagulant effect. These coagulation changes are poorly understood but may involve alterations in platele function. The Sonoclot analyser allows measurement of a number of parameters of whole blood coagulation. After platelet activation CD62P ( $\mathrm{P}$ selectin) expression is increased on the surface membrane of the platelet. CD42a (GPIX) is also expressed on the platelet surface and CD45 on leucocytes but not platelets. Platelet-leucocyte aggregates (CD45-CD42a positive events) may be increased in thrombotic states. Monoclonal antibodies to these antigens can be conjugated to fluorescent molecules and analysed by flow cytometry.

Aim-The purpose of this study was to investigate the effect of in vivo haemodilution with $0 / 9 \%$ sodium chloride and Gelofusine on whole blood coagulation, platelet activation and platelet-leucocyte interaction.

Methods-The study was performed as a randomised, controlled, crossover study. Eigh adult volunteers received $1000 \mathrm{ml}$ of each solution over 30 minutes on separate occasions with a one week washout period between tests. Atraumatic blood sampling was performed from a free flowing upper limb vein before and immediately after fluid infusion. Fresh blood was used for Sonoclot analysis. Blood for platelet analysis was collected into sodium citrate containing vacutainers and analysed within 10 minutes of collection.

Results-Mean Sonoclot values and platelet molecule expression pre/post solution are presented in table 1.

Conclusions-In vivo haemodilution with Gelofusine significantly prolongs the time to reach maximum clot strength. Other whole blood coagulation parameters are unaltered. Both platelet activation and platelet-leucocyte

Table 1

\begin{tabular}{lllllll}
\hline & Before saline & After saline & Change & $\begin{array}{l}\text { Before } \\
\text { colloid }\end{array}$ & After colloid & Change \\
\hline Peak $(\mathrm{s})$ & 1142 & 1281 & 139 & 1168 & $2200^{\star \star}$ & 1032 \\
Rate & 19.7 & 19.8 & 0.1 & 19.7 & 18 & 1.7 \\
ACT & 120 & $97^{\star}$ & -23 & 118 & 115 & -3 \\
Maximum amplitude & 75 & 76 & 1 & 73 & 75 & 2 \\
CD 62P & 1.42 & 2.19 & 0.766 & 1.31 & 0.95 & -0.363 \\
CD45-CD42a & 4.55 & 7.12 & 2.57 & 5.37 & 3.46 & -1.91 \\
\hline
\end{tabular}

${ }^{\star \star} \mathrm{p}=0.009,{ }^{\star} \mathrm{p}=0.016$, paired $t$ test.

interaction are impaired by Gelofusine in contrast with saline, which promotes these changes.

A prospective randomised controlled trial to investigate the clinical and cost effectiveness of emergency physiotherapy SUSAN J BUTTRESS, KEVIN MACKWAY-JONES, JACKIE OLDHAM

Accident and Emergency Department, Manchester Royal Infirmary, Oxford Road, Manchester, M13 9WL

Background-Musculoskeletal problems account for a high proportion of patients attending emergency departments. As many as one third of patients have musculoskeletal problems. The most common pathway is for patients to be placed on an outpatient waiting list with considerable delays. The result is that acute physiotherapy is rarely provided. An alternative pathway is for emergency department physiotherapy delivering treatment earlier than would otherwise be possible. Earlier intervention may not only reduce the duration of acute symptoms and length of treatment but also affect the long term outcome. There is evidence to suggest that this is the case.

Objective-To investigate the clinical and cost effectiveness of an emergency physiotherapy service.

Design-Prospective randomised controlled trial.

Setting-An inner city teaching hospital.

Subjects - Adult patients attending the emergency department with soft tissue injuries of the knee, ankle and neck that are assessed as suitable for physiotherapy by the emergency physician. Patients were randomised into either an emergency physiotherapy group or a traditional late physiotherapy group.

Main outcome measures-Clinical outcome was assessed using the short form-36, and the EuroQol questionnaires. The cost of each patient episode was determined from patient data.

Results-Each patient subgroup was randomised producing three separate trials. Analysis was performed using the different dimensions of the SF-36. There were significant differences between the emergency group and the traditional treatment group $(\mathrm{p}<0.05)$ in the ankle and knee subgroups. There was no significant difference in the neck subgroup. Conclusions-This study has demonstrated that the early treatment of soft tissue injuries of the knee and ankle is more effective than 
treatment by the traditional method of a delayed service.

\section{Identifying and managing risks in emer- gency medicine}

M THOMAS, K MACKWAY-JONES, N BOREHAM EMERGE Office, Department of Emergency Medicine, Manchester Royal Infirmary, Manchester M13 9WL

Objectives-To investigate the underlying causes of clinical risks in emergency departments (EDs). To suggest appropriate countermeasures to these underlying causes.

Design-Prospective observational study involving identification of critical incidents in EDs by staff incident reporting, by direct observation, and by daily review of patients' records. Derivation of causal trees for each incident identified with classification of root causes, obtained from the causal trees, using a risk management tool known as MECCA (Medical Errors Complications and Causal Analysis). Comparison of root causes between different EDs by Kruskall-Wallis and MannWhitney tests. Production of countermeasure profiles for each ED using a matrix derived for this purpose.

Setting-Four UK EDs, studied for six matched one week periods.

Main outcome measures-Root cause profiles of critical incidents in each ED.

Results -349 critical incidents were studied, giving 852 root causes. Some $3.6 \%$ of root causes were technical in nature, indicating that equipment inadequacies are not a common cause of risks in EDs. The majority of root causes were human $(42.1 \%)$ or organisational $(34.6 \%)$ in nature. The remainder of root causes involved patient related factors $(14.8 \%)$ or were unclassifiable $(4.8 \%)$. Significant differences $(\mathrm{p}<0.001)$ were detected between EDs for three subcategories of root cause. These were root causes relating to lack or inadequacy of protocols or guidelines in use within the EDs; those relating to collective behaviour; and those relating to organisational factors outside the departments (mainly attributable to bed shortages). The countermeasure profiles for each ED differed, reflecting the different underlying causal factors of risks in the EDs.

Conclusion-Most critical incidents in EDs are related to human or organisational factors. MECCA analysis can detect significant differences in the causal factors of risk between EDs, and thus focus countermeasures appropriately.

Can serum S-100B level predict an adverse outcome following head injury? W J K TOWNEND, M A PANI, J M GUY, D W YATES Department of Emergency Medicine, Hope Hospital, Salford

Objective-Patients with head injuries of any apparent severity at presentation can experience significant, long term morbidity. A serum marker of brain injury that provided an indication of potential complications would be a valuable addition to our diagnostic armoury. $\mathrm{S}-100 \mathrm{~B}$ is a protein expressed almost exclusively in astroglial cells of brain tissue that crosses the blood brain barrier in measurable quantities following brain injury. The aim of this study is to evaluate serum S-100B level as a predictive test for adverse outcome following head injury of any apparent severity at presentation.

Methods-Patients with head injury of any severity (GCS 3-15) attending the emergency departments of two hospitals in Manchester were included in this prospective study. Serum S-100B levels were measured within six hours of injury, and patient outcome assessed at one month using the extended Glasgow Outcome Score (GOSE)

Results - 94 patients have been recruited to date, and 24 of these have now been followed up. A further 300 will be recruited in the next four months. Initial data analysis shows a significant correlation between serum S100B level and GOSE (Spearman's $\rho=-0.564 ; \mathrm{p}=$ $0.004)$. Analysis of data for the subgroup of patients attending with initial GCS $15(n=20)$ revealed a significant correlation also (Spearman's $\rho=-0.450 ; p=0.047)$.

Conclusion-In a heterogeneous population with predominantly mild head injury we found a significant correlation between S-100B level measured within six hours and neurological outcome at one month. S-100B level may have a role as a predictor of adverse outcome in those patients who present with an initial GCS of 15.

The effect of the right and left lateral recovery positions on vena caval diameter

KRISTIAN BAILEY, LESLEY BETHUNE, KEN UZOKA, I STUART

No address supplied

Background - The lateral recovery position is recommended for patients with reduced airway protective reflexes. Anaesthetic prac tice favours the left lateral recovery position while standard resus texts do not state a preference. Previous unpublished work (by JS) demonstrated a significant fall in stroke distance in the left lateral recovery position but not the right lateral recovery position. The physiological mechanism for this observation was unclear.

Objectives - To determine the effects of the left and right lateral recovery positions on the diameter of the inferior vena cava.

Method-Thirty healthy volunteers had their vena caval diameter measured (and cross sectional area calculated) by ultrasound imaging in three positions; supine, left lateral recovery and right lateral recovery. The changes were expressed as percentage change from supine. Results - There was a mean fall in IVC cross sectional area in the left lateral position of $48.9 \%(\mathrm{p}<0.05)$ while the IVC cross sectional area increased by $62 \%(p<0.05)$ in the right lateral recovery position. This effect was due to direct compression by the liver.

Conclusion-This observation would explain the previously observed fall in stroke distance in the left lateral recovery position in terms of caval compression by the liver. From a cardiovascular perspective, the right lateral recovery position is superior to the left lateral position.

Oral presentations: Paediatric emergencies and others

Nasal diamorphine for acute paediatric pain: a multi-centre randomised controlled trial

JASON KENDALL, BARNABY REEVES, VICTORIA LATTER

Frenchay Hospital, Frenchay Park Road, Bristol, BS16 1LE

Objective-To evaluate the efficacy and safety of nasal diamorphine (ND) as an analgesic agent for use in children in the emergency department (ED).
Methods-Prospective, randomised, multicentre controlled trial (following Good Clinical Practice guidelines) comparing ND (0.1 $\mathrm{mg} / \mathrm{kg}$ ) with intramuscular morphine (IMM) $(0.2 \mathrm{mg} / \mathrm{kg})$. Eight centres recruited children (aged 3 to 16 years) with clinically suspected limb fractures. Outcome measures included tolerance to, and acceptability of, administration of analgesic, pain scoring (at baseline, 5 10,20 and 30 minutes after analgesic administration), physiological measures (pulse, respiratory rate, GCS and oxygen saturation at baseline, 5, 10, 20 and 30 minutes), and adverse events.

Results -410 children were recruited (IMM = 203 , ND $=207$ ). Demographic and potentia confounding factors were equally distributed between the two groups. Tolerance and acceptability measures were significantly better in the ND group $(\mathrm{p}<0.001)$. Baseline pain scores were the same in both groups. Pain scores as reported by the child were significantly better at 5,10 and 20 minutes in the ND group $(\mathrm{p}=0.04, \mathrm{p}=0.006$, and $\mathrm{p}=0.003$ respectively). There was no significant difference in pain scores at 30 minutes. Parental reporting of pain scores showed a similar distribution with similar statistical significance. There were no differences between the groups in physiological variables measured, with the exception of oxygen saturation, where a statis tically significant reduction in oxygen saturation was observed at 5,10 and 20 minutes in the ND group; this was, however, not clinically significant. There were no serious adverse events; there was one moderate adverse event in the IMM group; there were several minor adverse events in both groups.

Conclusions - ND is an effective, safe and well tolerated method of analgesia for children in acute pain in the ED.

Magnetic resonance imaging in the management of paediatric scaphoid injuries E SYMONDS, F HAIGH, K JOHNSON

The Birmingham Children's Hospital, Steelhouse Lane, Birmingham B4 6NH

Background-The scaphoid is the most commonly fractured carpal bone. Plain radiographs are poor at detecting scaphoid fractures at initial presentation. The consequences of missed scaphoid fracture can be serious and increasingly other imaging modalities are being used to detect scaphoid fractures. We present our work on the routine use of magnetic resonance imaging (MRI) in the paediatric population to detect scaphoid fractures early. Methods-All children presenting to the Birmingham Children's Hospital emergency department with a suspected scaphoid fracture had an initial "scaphoid radiography" series and were immobilised appropriately. At early clinical review those patients in whom there was clinical suspicion of a scaphoid injury were referred for MRI. The MRI was performed within 10 days of the initial injury. The MRI was regarded as the definitive investigation for the scaphoid injury and those patients who had a negative MRI were discharged from care. Those patients with a positive MRI were treated appropriately. Results - 114 children had scaphoid MRI, they aged from 4.5 to 16 years ( 73 boys). All children tolerated the MRI scanner. Forty two of the examinations were positive for a scaphoid fracture $(39 \%)$. Additionally, other carpal bone fractures, soft tissue injuries and ganglion cysts were identified on the MRI and were treated appropriately. There were 51 negative examinations (48\%). All these chil- 
dren were discharged from care. None of this negative group has represented.

Conclusions-MRI can be routinely used in a busy paediatric emergency department to exclude a scaphoid injury. The routine use of MRI avoids the children having repeat plain film radiographs and confirms or refutes the diagnosis of a scaphoid fracture early. Those children having a negative examination can be discharged from care avoiding unnecessary immobilisation and treatment. The use of MRI for scaphoid injuries reduces patients' attendance at hospital, improves diagnostic accuracy and improves patient care.

Whiplash associated disorder in children-an emergency department based study

R BOYD ${ }^{\star}$, L DUANE ${ }^{\star \star}$, R MASSEY $^{\star \star \star}$, D YATES ${ }^{\star \star \star}$ ${ }^{\star}$ Department of Emergency Medicine, Hope Hospital, ${ }^{\star \star}$ Department of Accident and Emergency Medicine, Booth Hall Childrens Hospital, ${ }^{\star *}$ Department of Accident and Emergency Medicine, Royal Liverpool Childrens Hospital, ${ }^{*} * \star A c a-$ demic Department of Emergency Medicine, Hope Hospital

Aims - To determine the incidence, severity and course of whiplash associated disorder (WAD) in children aged 4-16 years after involvement as a passenger in a road traffic accident (RTA).

Methods-Prospective surveillance of all paediatric attendances to three UK urban emergency departments following RTAs for a six month period. An initial structured telephone interview at day 2 after the RTA was followed by selective clinical review utilising the Quebec Task Force criteria for outcome assessment. Results - One hundred and one children were identified as having been involved in a RTA as a passenger. Forty three experienced symptoms of a WAD (42.5\%). Thirty six experienced a WAD of grade 1 with seven experiencing grade 2 severity. There was no significant age difference between the children who did and did not develop WAD symptoms. Twenty five of the children developing WAD were female $(58 \%)$. The mean duration of symptoms was 8.5 days (range $3-70$, SD 10.7). Sixty one children developed symptoms within 24 hours $(60 \%)$ with the remainder developing symptoms by 48 hours.

Conclusions-Despite the paucity of published evidence, WAD does occur in children. The incidence of WAD in children is in fact similar to that found in adult studies. This study suggests that the clinical course however is more favourable in children than that in adults.

Limitations of this study - This pilot work lacks sufficient numbers to enable meaningful statistical analysis of subgroups. Inherent bias exists relating to the selection bias of children presenting to the emergency department.

What does the paper offer that is new to the field? - This is the first prospective study of the incidence and clinical course of WAD in a paediatric population.

What is a normal systolic blood pressure and pulse rate in an injured child?

PAUL DARK, MARALYN WOODFORD, ANDY VAIL, KEVIN MACKWAY-JONES, DAVID YATES

MRC TRAUMA GROUP (NWIRC), Stopford Building, Oxford Road, University of Manchester, Manchester M13 9PT

Objective-To determine the effect of injury on "normal" age related systolic blood pressures and pulse rates in children.
Design - Nine year prospective cohort study. Setting-Participating emergency departments in the Trauma Audit and Research Network (TARN)-formerly UK Major Trauma Outcome Study.

Subjects-All injured children below 16 years of age and who were eligible for inclusion in the TARN database.

Main outcome measures-Age specific systolic blood pressure $(\mathrm{mm} \mathrm{Hg}$ ) and pulse rates (per minute) in injured children were compared with standard quoted values for resting children and with Advanced Paediatric Life Support "norms". The Injury Severity Score was used to categorise by anatomical injury severity.

Results-Advanced Paediatric Life Support age specific "norms" of systolic blood pressure and pulse rate resembled standard quoted values for children at rest. Our cohort of over 10000 injured children had higher systolic blood pressures than would be expected from the standard quoted "norms". These norms for children at rest always appeared below the 50 th centile for injured children (range 7 th to 27 th centile). This relative systolic hypertension in injured children appeared unrelated to injury severity and age. Pulse rate norms for children at rest were always within the interquartile range for injured children (range 41 st to 54th centile) and did not appear influenced by age or injury severity.

Conclusion-Injured children have a relative systolic hypertension on arrival in the emergency department, compared with children a rest. However, pulse rates in these two group are comparable. Age related systolic blood pressures and pulse rates may be poor indicators of haemodynamic status of children after injury.

Occupational stress in consultants in accident and emergency medicine: a national survey of levels of stress at work SUSAN ROBINSON ${ }^{\star}$, RACHEL BURBECK ${ }^{\star \star}$, SALLY COOMBER $^{\star \star}$, CHRIS TODD ${ }^{\star \star \star}$

${ }^{\star}$ Emergency Medicine, Addenbrookes NHS Trust, ${ }^{\star *}$ Occupational Medicine and ${ }^{\star * *}$ Institute of Public Health, University of Cambridge, Addenbrooke's NHS Trust, Hills Road, Cambridge CB2 $2 Q Q$

Background-Occupational stress is a recog nised problem in healthcare workers, and doctors are considered to be at special risk. ${ }^{1} \mathrm{~A}$ number of surveys suggest that about a quarte of senior doctors are distressed or depressed. ${ }^{2}$ Among emergency physicians, available data, primarily from the US, suggest that the problem of burnout and stress may exist to considerable degree. ${ }^{4}$ However, to date little work has been carried out in the UK

Objective-To measure the prevalence of occupational stress as measured by psychological morbidity and depression among accident and emergency (A\&E) consultants in the UK.

Method-Postal survey of practising BAEM FAEM members incorporating the Genera Health Questionnaire-12 (GHQ-12) and Symptom Checklist-Depression Scale (SCL-D)

Results-From a $78 \%$ response rate (371 of 479 ), $45.6 \%$ of respondents had GHQ-12 scores indicative of psychiatric disorder (GHQ-12 > 3), and $18.1 \%$ had an SCL-D score indicative of depression. Women had significantly higher SCL-D scores than men $(\mathrm{U}=6604, \mathrm{p}<0.009)$. Scores on both measures rose with the numbers of hours worked, and there was a significant association be- tween GHQ-12 score and hours worked for those working full time $(\rho=0.126, p<0.028$, $\mathrm{n}=318$ ). Respondents were highly satisfied with their choice of $A \& E$ as a specialty. Their most highly rated stressors were: "lack of beds within the main hospital", "being overstretched at times" and "the effect of hours of work on personal/family life".

Conclusions-Despite being highly satisfied with $A \& E$ as a specialty, large numbers of $A \& E$ consultants seem to be suffering from symptoms indicative of psychological distress. Chief stressors seem to be factors outside of the specialty itself. The most highly ranked suggestions for relieving stress were: the availability of experienced middle grade doctors 24 hours a day, having managers who understand the issues within $\mathrm{A} \& \mathrm{E}$, and resolving delays in patient transfers out of A\&E

1 Stress at work - a guide for employers. HS(G) 116. London: HSE Books, 1995

2 Kapur N, Borrill C, Stride C. Psychological morbidity and job satisfaction in hospital consultants and junior house officers: multicentre, cross sectional survey. $B M 7$ 1998;317:511-12.

3 Blenkin H, Deary I, Sadler A, et al. Stress in NHS Blenkin H, Deary 1, Sadler A, et

4 Doan-Wiggins L, Zun L, Cooper MA, et al. Practice satisfaction, occupational stress, and attrition of emergency physicians. Acad Emerg Med 1995;6: $556-63$.

The scientific basis of the refined casemix measure for the specialty of accident and emergency medicine (HRG version 2.2)

N F BRAYLEY, MEMBERS OF THE CASEMIX SUBCOMMITTEE OF THE CLINICAL SERVICES COMMITTEE OF BAEM AND THE CASEMIX OFFICE OF THE NHS INFORMATION AUTHORITY

Emergency Department, Colchester General Hospital

The development of a robust casemix measure for the specialty of accident and emergency (A\&E) medicine is desirable to secure appropriate funding for the resources necessary to meet the varying demands for patient care provided in different departments from one year to the next.

This presentation explains the development of Healthcare Resource Group (HRG) version 2.2, the role of classification and regression trees (CART) analysis to produce the casemix measure nodes that give the new version a reduction in variance (RIV) of $64 \%$. Investigations and disposal are the key nodes identified from a refined UK database of over 100000 episodes prepared in 1999 from five different types of $\mathrm{A} \& \mathrm{E}$ departments.

The role of the national Triage Scale as a casemix measure was considered but found not to be as robust as disposal.

The Australian casemix measure based on Triage provides a similar RIV but found not to be reproduced with the English dataset.

From June 2000 HRG casemix returns will be mandatory for each English A\&E department. The possibilities for further refinement work and practical applications for HRGs will be discussed.

\section{$\underline{\text { Trauma }}$}

Improving prediction of outcome from major trauma

HIU NAM TONG, SALLY HOLLIS, ALAN WROTHFORD Trauma Audit \& Research Network, Clinical Sciences Building, Hope Hospital, Stott Lane, Salford M6 $8 H D$

Objective - To determine the impact of adding pre-existing disease status to the TRISS formula. 


\begin{tabular}{llllll}
\hline Model & H-L score & Sensitivity (\%) & Specificity (\%) & Accuracy (\%) & $\begin{array}{l}\text { Area under ROC (95\% } \\
\text { confidence intervals) }\end{array}$ \\
\hline A & 70.3 & 99.32 & 35.46 & 95.97 & $0.925(0.920,0.930)$ \\
B & 42.5 & 99.26 & 36.20 & 95.96 & $0.929(0.925,0.934)$ \\
C & 36.2 & 99.33 & 38.64 & 96.15 & $0.940(0.936,0.944)$ \\
D & 34.2 & 99.34 & 38.75 & 96.17 & $0.941(0.937,0.945)$ \\
\hline
\end{tabular}

Method-The study was based on Trauma Audit and Research Network data from 1994-98 inclusive. Revised Trauma Score (RTS), Injury Severity Score (ISS), age and pre-existing disease (PMC) status were recorded in 53954 cases. Logistic regression models were produced for four configurations using a split sample validation technique. $\mathrm{A}=$ Standard TRISS components (age 0-54, 55+); $\mathrm{B}=\mathrm{A}$ plus PMC status (present, absent, not recorded); $\mathrm{C}=\mathrm{A}$ with age profile $0-54$, 55-64, 65-74, 75-84, 85+; D=C plus PMC status (present, absent, not recorded). PMC was defined as respiratory, renal, liver or ischaemic heart disease, diabetes mellitus or congenital coagulopathy.

Results-The results are shown in table 2 . Hosmer-Lemeshow (H-L) score is a goodness of fit statistic. A lower score indicates a better fit of data. All results were highly significant $(p<0.0001)$ but this is to be expected because of the very large sample size. ROC is the receiver operating characteristic curve that compares sensitivity and specificity in graphical form. The area under the curve should approach unity.

Discussion - The addition of PMC status (model B) to the standard TRISS model A appears to give a better prediction according to both the H-L score and the area under the ROC curve. There is a greater gain, especially with the ROC curve, from refining the age groups into deciles above age 55 (model C) to which the inclusion of PMC status has little to add (model D). This may be because the refinement in age grouping will account for most of the PMC effect, as prevalence of preexisting disease rises with increasing age.

Conclusion-Analysis of almost 54000 patient data files reveals that better prediction of outcome can be achieved by adding either pre-existing disease status or a better profile of age to the existing TRISS formula. The latter is more reliable and is therefore recommended.

Diaphragmatic rupture and the association with occupant position in right hand drive vehicles

SHOBHAN THAKORE, JENNY HENRY, ALISTAIR W TODD, SHOBHAN THAKORE

Ninewells Hospital, Dundee DD1 9SY

Ruptured diaphragm following blunt trauma occurs with an incidence of $5 \%$ in those requiring laparotomy. It was initially reported as almost entirely a left sided phenomenon, however right sided rupture is now recognised with increasing frequency. The vast majority of case series have come from countries where vehicles are left hand drive. This study aimed to investigate the influence of occupant position in right hand drive (RHD) vehicles on the side of diaphragmatic injury.

An analysis of the Scottish Trauma Audit Group database was performed to gather data on blunt diaphragmatic lacerations reported between 17 April 1992 to 16 May 1999. Drivers and front seat passengers (FSPs) were included in the analysis. Table 3 shows the admission characteristics of patients and table with ruptured diaphragms

\begin{tabular}{lll}
\hline & Drivers & FSPS \\
\hline Total number & 25 & 10 \\
Male & 22 & 4 \\
Female & 3 & 6 \\
Mean age & 32.8 & 32.6 \\
Median ISS & 34 & 31.5 \\
Median SBP & 115 & 122.5 \\
Median GCS & 14 & 15 \\
Left sided rupture & $13(60 \%)$ & $8(80 \%)$ \\
Right sided rupture & $10(40 \%)$ & $2(20 \%)$ \\
Bilateral rupture & 2 & 0 \\
MV $v$ MV & 17 & 3 \\
MV $v$ other & 7 & 4 \\
\hline
\end{tabular}

4 shows their associated injuries. In total, 35 patients were studied, 25 drivers and 10 FSPs. The incidence of right sided rupture was $40 \%$ in drivers and $20 \%$ in FSPs. The incidence of associated pulmonary contusion, rib fracture and liver injury was also higher in drivers. Given the small sample size, these differences were not statistically significant but show an interesting trend.

Ruptured diaphragm following blunt trauma was initially thought to involve the left side almost exclusively. However, a higher index of suspicion and accidents occurring at greater speeds has seen right sided ruptures reported with increasing frequency. The mechanism of rupture is thought to be a sudden rise in intra-abdominal pressure following a compressive force. The role of lateral shearing forces has also been advocated as a cause of rupture. Our results may reflect the fact that the right side of the driver's body is more exposed to injury in RHD vehicles, a feature of particular importance in the UK. As right sided injury is more difficult to detect, it is important that a high index of suspicion is maintained especially when managing injured drivers from RHD vehicles.

Table 4 Associated injuries in drivers and FSPs with ruptured diaphragms

\begin{tabular}{lll}
\hline & $\begin{array}{l}\text { Drivers } \\
\text { number }\end{array}$ & $\begin{array}{l}\text { FSPs } \\
\text { number }\end{array}$ \\
\hline Chest injuries & 14 & 2 \\
Ribs (n) & 10 & 4 \\
Haemothorax & 8 & 3 \\
Pneumothorax & 17 & 3 \\
Pulmonary contusion & 4 & 0 \\
Flail segment & 2 & 2 \\
Myocardial contusion & 2 & 0 \\
Mediastinal haemorrhage & 2 & 1 \\
Aortic injury & & \\
Abdominal injuries & 15 & 3 \\
Liver injury & 11 & 6 \\
Splenic injury & 3 & 4 \\
Mesenteric injury & 3 & 0 \\
Large bowel injury & 2 & 0 \\
Small bowel injury & 5 & 0 \\
Renal injury & 9 & 9 \\
Pelvic (n) & 5 & 2 \\
Vertebral (n) & 7 & 1 \\
Severe head injury & & \\
\hline
\end{tabular}

^Number of patients.
Table 3 Admission data of drivers and FSPS
Mathematical modelling in the development of a trauma system

T J COATS, S ROBBINS, C LOWDELL, M DAMIANI Accident and Emergency Department, Royal London Hospital, Whitechapel, London E1 $1 B B$

Current systems of emergency care are often based on historical accident rather than design. The London Severe Injuries Working Group has reviewed trauma care in Greater London. To test the effects of different configurations of trauma system a novel approach was adoptedmathematical modelling.

The inputs to the model were: (1) the geographical distribution of injury (from ambulance service data); (2) the critical and definitive interventions for each type of injury; (3) the optimum timing of interventions and specialists/facilities required (from a clinical consensus conference); (4) the relative proportions of different combinations of injuries (from UK national trauma data); (5) the locations of hospitals and the specialist services available in each; (6) the time taken to move a patient to various hospitals (from mapping and drivetime software); (7) flow charts for possible treatment routes for the 19 commonest types of injury.

Key outputs from the model were (a) the time taken to achieve critical interventions and (b) the time to definitive intervention (for example, surgery).

The different configurations of trauma system that were then tested included: (1) decreasing the length of time spent prehospital by the ambulance service; (2) decreasing the time taken in hospitals before reaching specialist care; (3) pre-hospital triage to bypass local hospitals if appropriate specialist care was within 20 minutes travel time from the accident scene; (4) inclusion of the London Helicopter Emergency Medical Service (HEMS). Maps were then drawn to illustrate numbers and geography of patients meeting clinical targets. For example, the proportion of patients with intracranial haematomas that reached a neurosurgeon within four hours was $20 \%$ if all patients were transported to the nearest hospital, $52 \%$ if both ambulance and hospital times decreased and HEMS was included, and $90 \%$ if all patients within a 20 minute radius of a specialist centre were taken there rather than the nearest hospital.

This is a novel approach to the development of trauma services. The method is time consuming, but once programmed the mathematical model allows the clinical effect of different options to be tested, and quantifies the trade offs between time to critical intervention and time to definitive intervention.

Role of neutrophil L-selectin in posttraumatic organ failure

T H RAINER, N Y L LAM, T Y F CHAN, R A COCKS Accident and Emergency Medicine Academic Unit, The Chinese University of Hong Kong and Prince of Wales Hospital, Hong Kong

Objective-To determine whether early numerical and functional changes in circulating neutrophils, the expression of neutrophil and soluble L-selectin predict the development of post-traumatic complications.

Methods-Ethical approval was obtained for a prospective, observational study to investigate the immune response of patients to injury. Neutrophil counts, expression of L-selectin (mean channel fluorescence, $\mathrm{mcf}$ ) and soluble L-selectin (sL-selectin) were measured using cell counters, flow cytometry and ELISA in 
164 trauma patients (mean (SD) age 39 (15) years; $81 \%$ male) triaged to an emergency department resuscitation room within four hours of injury (median 60 minutes; interquartile range 50, 90; range 30-240). The primary outcome measures were organ failure (OF; n=51), multiple organ dyfunction syndrome (MODS; $\mathrm{n}=20$ ), acute lung injury (ALI; $\mathrm{n}=10)$ and mortality $(\mathrm{n}=21)$. All values (means (SD)) were analysed with the MannWhitney U test.

Results - Neutrophil counts were higher in those who developed OF $\left(9.5(5.1) \times 10^{9} / \mathrm{ml} v\right.$ $\left.12.1(7.1) \times 10^{\circ} / \mathrm{ml} ; \mathrm{p}<0.05\right)$ and ALI $(10.1$ $\left.(5.6) \times 10^{9} / \mathrm{ml} v 15.9(7.9) \times 10^{9} / \mathrm{ml} ; \mathrm{p}<0.02\right)$. Neutrophil L-selectin mcf was higher in those who developed OF (7.9 (3.4) v 9.2 (3.2); $\mathrm{p}<0.05)$. Soluble L-selectin levels were lower in those who developed OF (763 (231) ng/ml v 670 (243) $\mathrm{ng} / \mathrm{ml} ; \mathrm{p}=0.06)$, MODS (764 (228) $\mathrm{ng} / \mathrm{ml} v 630$ (239) ng/ml; $\mathrm{p}=0.08)$, ALI (764 (226) ng/ml $v 563(228) \mathrm{ng} / \mathrm{ml} ; \mathrm{p}<0.05)$ and in those who died (757 (230) ng/ml v 523 (209) $\mathrm{ng} / \mathrm{ml} ; \mathrm{p}<0.01)$. The ratio of total neutrophil L-selectin (neutrophil count $x$ neutrophil mcf $\times \%$ neutrophils expressing $\mathrm{L}$-selectin) to sL-selectin was higher in those who developed OF (0.2 (0.1) $v 0.1(0.08)$; $\mathrm{p}<0.0001)$, MODS (0.11 (0.09) $v 0.21$ $(0.13) ; \mathrm{p}<0.005)$, ALI (0.3 (0.1) v $0.1(0.09)$; $\mathrm{p}<0.005)$ and in those who died $(0.21(0.16)$ $v 0.12$ (0.09); $\mathrm{p}=0.09)$.

Conclusion-Changes in neutrophil L-selectin expression may have prognostic value for post-traumatic complications. An early imbalance in the relation of neutrophil to plasma L-selectin favours the development of posttraumatic organ failure.

Systemic arterial pressure wave reflections during haemorrhage

P M DARK, J PURDY, J ATHERTON, D DODDS, R A LITTLE

MRC Trauma Group (NWIRC), Stopford Building, University of Manchester, Oxford Road, Manchester M13 9PT

Objective-To determine the contribution from pressure wave reflection to systemic arterial blood pressure shape during a survivable haemorrhage $(25 \%)$ and during reinfusion of shed blood.

Design — Prospective randomised control laboratory experiment.

Subjects - Saffan anaesthetised and mechanically ventilated immature large white pigs.

Main outcome measures-Aortic reflection wave ratio (Augmentation Index) was determined at the input to the systemic circulation $\left(\mathrm{AI}_{\mathrm{aa}}\right)$ and the input to the trunk circulation $\left(\mathrm{AI}_{\mathrm{d}}\right)$ using high fidelity digital recordings of intravascular pressure contours. Thermodilution derived global haemodynamics, oxygen transport and oxygen metabolism parameters were recorded simultaneously.

Results-AI ${ }_{a 2}$ fell from control to posthaemorrhage values $(0.42 \pm 0.14,(n=25)$, to $0.25 \pm 0.18,(\mathrm{n}=18), \mathrm{p}<0.05)$ and recovered after re-infusion of shed blood compared with the control group $(0.45 \pm 0.14,(\mathrm{n}=9), v 0.44$ $\pm 0.13,(n=7), p>0.05) . A_{d a}$ followed a similar pattern after haemorrhage, although 8 of 18 developed a negative value $(-0.35 \pm 0.22$, $(\mathrm{n}=8), v 0.20 \pm 0.20,(\mathrm{n}=10), \mathrm{p}<0.05)$ with associated conservation of a positive $\mathrm{AI}_{\mathrm{an}}(0.17$ $\pm 0.08,(\mathrm{n}=8), v 0.30 \pm 0.22,(\mathrm{n}=10), \mathrm{p}>0.05)$. $\mathrm{A}$ negative $\mathrm{AI}_{\mathrm{da}}$ following haemorrhage was associated with the worst thermodilution derived global haemodynamics.
Conclusions-Pressure wave reflections within the systemic arterial circulation are known to be important in determining aorto-ventricular coupling in health and in chronic systemic hypertension. In this study, pressure wave reflection measured at the inputs to the systemic circulation and the trunk circulation were reduced during survivable haemorrhage and recovered after re-infusion of shed blood. After haemorrhage, a negative $\mathrm{AI}_{\mathrm{da}}$ with conservation of a positive $\mathrm{AI}_{a \mathrm{a}}$ was associated with the wors haemodynamic profiles. This pattern of change indicates that pressure wave reflection towards the left ventricle from the lowe limbs is reduced during haemorrhage and gradually replaced by a predominant reflection site originating from within the trunk arterial system. Such changes may not favour optimal aorto-ventricular coupling during the evolution of haemorrhagic shock.

From "ambulance volantes" to accident and emergency squads-is deployment still appropriate?

J J MCINERNEY, M NORWOOD, G LLOYD, D QUINTON The Leicester Royal Infirmary, Infirmary Close, Leicester LE1 5WW

Introduction - Similar to Baron Larrey's "ambulance volantes" deployed during the Napoleonic wars, accident and emergency (A\&E) flying squads today provide assistance "in the field", despite a paucity of evidence to suppor their continuing use alongside modern paramedics. The aim of this study was to evaluate the appropriate deployment of a flying squad.

Methods-A prospective survey of all serious trauma patients attending $\mathrm{A} \& \mathrm{E}$ over one year. Ambulance control, which activates the squad, was kept blind to the study. Trauma team leaders completed a structured proforma in every case, assessing appropriate squad development, listing interventions, an documenting time out of A\&E. Revised trauma scores (RTS), injury severity score (ISS), inpatient stay and death were also determined.

Results - 221 patients were included of which 15 incidences involved squad deployment. Demographic data for both the squad (S) and non-squad (NS) groups were comparable. Appropriate deployment occurred in 10 of 15 call outs, while in 2 of 206 instances the squad was under-utilised. Opioid administration was the most frequent squad intervention. Mean squad time was 73 minutes (range 40-185). A RTS $<8$ existed in 3 of 15 in group $\mathrm{S}(20 \% ; 95 \% \mathrm{CI}=0.11,0.61)$ compared with 33 of 206 in group NS (16\% $95 \% \mathrm{CI}=0.11,0.21$ ). Mean (SD) inpatien stay differed between group ( $\mathrm{S}=11.5$ (11.9) days; NS=9.8 (18.5) days), but there was no difference in mortality $(\mathrm{S}=1$ of 15 ; $95 \% \mathrm{CI}=0.001, \quad 031: \quad \mathrm{NS}=14 \quad$ of 206 $95 \% \mathrm{C} 1=0.03,0.11$ )

Conclusions-Although appropriate deployment of the flying squad was achieved, there was occasional delays in activation, as well as duplication of effort. Furthermore, despite obvious training benefits, routine deploymen of a flying squad has to be weighted agains the detrimental loss of senior staff from A\&E. A larger study is required to assess the cost effectiveness of continued flying squad provision.
Patients admitted from accident and emergency departments to intensive care units: a descriptive analysis using the ICNARC database and quantification of the effect of admission to a ward prior to intensive care unit, compared with direct admission from accident and emergency HOWARD SIMPSON, CAROLINE GOLDFRAD, KATHY ROWAN, MIKE CLANCY

Accident and Emergency Department, Southampton General Hospital, Tremona Road, Southampton SO16 6YD

Introduction-This is the first UK study to describe accident and emergency/intensive care unit $(\mathrm{A} \& \mathrm{E} / \mathrm{ICU})$ activity. The hypothesis is tested that admission to a ward prior to ICU leads to poorer outcome compared with direct admission from $\mathrm{A} \& \mathrm{E}$ to ICU.

Method-A retrospective analysis of the Intensive Care National Audit and Audit and Research Centre (ICNARC) database was performed. Ninety two ICUs have submitted data between 1996 and 1999. Admissions were categorised according to source: direc admissions from A\&E to ICU; indirect admissions who were admitted to a ward between $\mathrm{A} \& \mathrm{E}$ and ICU; and non-A\&E admissions to ICU. The case load, case mix and outcome of the three admission groups are described. Multivariate analysis is used to calculate the additional risk of death associated with admission to a ward.

Results-Of 46587 ICU admissions, 9389 were direct admissions from A\&E to ICU, 2789 were indirect admissions from $\mathrm{A} \& \mathrm{E}$ to ward before admission to ICU; 34319 were non-A\&E admission to ICU. Direct admissions were younger, more likely to be male, less likely to have a serious past medical history, more likely to present with trauma, more likely to be admitted out of hours and at weekends, and had the lowest predicted mortality and the shortest length of stay compared with the other two groups. Indirect admissions were more likely to present with respiratory and cardiac conditions, had the highest mean APACHE II scores, the highest predicted mortality, the greatest length of stay for survivors, and the highest mortality compared with the other two groups. Multivariate analysis demonstrated an excess mortality of 34\% (95\% confidence intervals: $19 \%, 52 \%$ ) associated with admission to a ward before ICU after adjustment for case mix (type and sensitivity of illness)

Conclusion - The case mix and case load of the three admission groups are as anticipated. However, the process of care among indirect admissions from A\&E to ICU must be investigated further to explain this apparent anomaly.

\section{Respiratory emergencies and others}

Effects of mask type, and method of ventilator triggering on tolerability of noninvasive ventilation: in chronic obstructive pulmonary disease after exercise I M STELL ${ }^{\star}$, S G ELLUM ${ }^{\star \star}$, J MOXHAM ${ }^{\star \star}$

${ }^{\star}$ Accident and Emergency Department, Bromley Hospital, Cromwell Avenue, Bromley, Kent BR2 $9 A \mathcal{A}$ and ${ }^{*}$ Department of Respiratory Medicine, King's College Hospital, Denmark Hill, London SE5 9RS

Success with NIPPV in acutely ill patients with chronic obstructive pulmonary disease (COPD) may be influenced by ventilator/ patient synchronisation and interaction. In this laboratory study nine patients with severe 
Aggregate VAS scores for theme (SD) $(n=9)$

\begin{tabular}{llll} 
& Help $(\max 40)$ & Panic (max 40) & $\begin{array}{l}\text { Loss of control } \\
\text { (max 40) }\end{array}$ \\
\cline { 2 - 4 } NIPPV modality & $31.1(2.4)$ & $6.3(1.7)$ & $8.0(2.1)$ \\
Control $\left(\mathrm{CPAP} 2 \mathrm{~cm} \mathrm{H}_{2} \mathrm{O}\right)$ & $32.4(4.4)$ & $6.3(3.7)$ & $5.7(4.3)$ \\
$\mathrm{RV}$ PAV & $34.6(4.0)$ & $6.5(3.9)$ & $4.6(2.9)$ \\
$\mathrm{Clinician}$ trigger & $30.2(6.5)$ & $9.3(5.1)$ & $7.9(4.5)$ \\
$\mathrm{RV}$ & $32.3(5.9)$ & $9.0(8.8)$ & $6.5(5.0)$ \\
Nippy 2: face mask & $28.8(9.3)$ & $11.3(6.4)$ & $7.1(4.8)$ \\
Nippy 2: nasal mask & $31.2(7.3)$ & $5.7(3.5)$ & $6.7(5.2)$ \\
Nippy 2: mouth piece & $27.1(7.3)$ & $9.9(6.3)$ & $9.9(6.0)$ \\
\hline
\end{tabular}

$\mathrm{RV}=$ Respironics Vision.

stable COPD (3F 6M), mean age 68, $\mathrm{FEV}_{1}$ 0.85 litres completed a questionnaire of 12 visual analogue scales (VAS), after using each of eight modalities of NIPPV (randomised, single blind) for five minutes after successive exhaustive treadmill walks. The NIPPV modalities included two comparisons: (a) between six different triggering/flow delivery systems, and (b) between different masks/mouthpiece. The NIPPV modalities included: a conventional flow triggered ventilator (Nippy 2), Proportional Assist Ventilation (PAV), which adjusts support from one breath to the next, a ventilator with software improved triggering (Respironics Vision), continuous positive airways pressure (CPAP) and a prototype ventilator in which the clinician controls the triggering with a button (as observation of the patient may allow accurate synchronisation). The following physiological parameters were also recorded each minute during ventilator use: $\mathrm{O}_{2}$ saturation, pulse, respiratory rate and breathlessness (Borg scale). The 12 VAS scales were aggregated into their underlying three themes: (a) the help given by the ventilator, (b) panic arising from using the ventilator, and (c) sense of loss of control of breathing.

Results - The results are shown in table 5. All of the physiological parameters recovered most rapidly when using PAV. In conclusion there was a strong trend for PAV to be the best tolerated form of ventilation, and the one with the most rapid recovery of the physiological measures recorded. This project was supported by the National Health Service R\&D (South Thames).

Endotracheal intubation in the accident and emergency department

J P BEALE, C A GRAHAM, S B THAKORE, E DOCHERTY, J BRITTLIFF, A OGLESBY, D BEARD, M A JOHNSTON, T R J PARKE

Department of Accident and Emergency Medicine, Royal Infirmary of Edinburgh, Lauriston Place, Edinburgh EH3 9YW

Introduction -Definitive airway control is fundamental to effective resuscitation. Endotracheal intubation represents the gold standard of airway management. It may be performed by both anaesthetists and emergency physicians with or without drugs.

Objective-The aim of this study is to characterise endotracheal intubation in the accident and emergency (A\&E) departments in six Scottish teaching hospitals.

Methods - A prospective multicentre observational study was set up under the auspices of the Scottish Trauma Audit Group. A proforma was completed at the time of intubation and subsequently checked by a local investigator in each site. This analysis reports on the first complete year of data collection (1999). Results-There were 773 intubations registered during the first year of this study. $\mathrm{A} \& \mathrm{E}$ doctors performed 536 intubations (69\%). A total of 277 patients were in non-traumatic cardiac arrest on arrival and they were intubated without the administration of anaesthetic drugs. Intubation without anaesthetic drugs was undertaken in a further 123 patients, 21 of whom had maintenance sedation given. These two groups are excluded from further analysis. Rapid sequence intubation (RSI) was performed on a total of 373 patients. Trauma patients constituted $45 \%$ (167) of the RSI group. RSI was performed on 107 patients (29\%) within 15 minutes of arrival. A\&E doctors intubated 194 patients $(52 \%)$. The overall complication rate was $7.5 \%$. There was no statistically significant difference in complication rates between $\mathrm{A} \& \mathrm{E}$ and anaesthetics when undertaking this procedure.

Conclusions-Endotracheal intubation and rapid sequence induction are performed by $\mathrm{A} \& \mathrm{E}$ doctors at least as frequently as by anaesthetists in the emergency department. The complication rates for both specialties are low and are comparable.

Facial continuous positive airway pressure therapy for cardiogenic pulmonary oedema: a study to assess its efficacy in an accident and emergency department setting within the UK

C READ, J J MCINERNEY, N O'CONNOR, M NORWOOD, P A EVANS

Accident and Emergency, Leicester Royal Infir mary, Infirmary Close, Leicester LE1 5WW

Introduction - Recent studies outside the UK suggest that patients with acute cardiogenic pulmonary oedema (CPO) may benefit from the application of facial continuous positive airway pressure (CPAP) support in emergency departments. The aim of this pilot study was to assess the impact of facial CPAP on patients with CPO within a UK A\&E department.

Methods - A prospective powered study comparing CPAP with supplemental oxygen at ambient pressure, using historical controls matched for CPO severity. Forty patients with internationally accepted criteria for CPO were included. Twenty patients received $20 \mathrm{~min}$ utes of facial CPAP using a dedicated Drager CPAP system with a $5 \mathrm{~cm} \mathrm{H}_{2} \mathrm{O}$ positive end expiratory pressure valve and maximal inspired oxygen (Group CPAP). Twenty controls received identical therapy but received maximal inspired oxygen via a nonrebreathing mask (Group C). Outcome measures compared were arterial partial pressures of oxygen and carbon dioxide, objective clinical signs, intubation rate and death. Statistica analysis was by a $t$ test and $95 \%$ confidence

Results-Patients receiving CPAP had a better improvement in arterial blood gas indices compared with controls, with higher mean oxygenation $(\mathrm{CPAP}=8.4 \mathrm{kPa}$ and $\mathrm{C}=3.5 \mathrm{kPa}$ $\mathrm{p}=0.017,(95 \% \mathrm{CI}=0.92$ to 8.77$)$, and better intervals (95\% CI). mean excretion of $\mathrm{CO}_{2}(\mathrm{CPAP}=-0.9 \mathrm{kPa}$ and $\mathrm{C}=+0.9 \mathrm{kPa}, \mathrm{p}=0.011$, (95\% CI $=-3.27$ to $-0.45)$. CPAP produced a higher mean reduction in respiratory rate, and lower mean reductions in blood pressure/pulse rate, although these were not statistically significant. The median length of inpatient stay $(\mathrm{CPAP}=4, \mathrm{C}=5$ days $)$ and intubation rates $(\mathrm{CPAP}=0, \mathrm{C}=3)$ differed between groups, but were not statistically significant. There was no difference in hospital mortality between groups $(\mathrm{CPAP}=3, \mathrm{C}=3)$.

Conclusions-CPAP utilisation in the A\&E department impacts favourably on the physiological manifestations of CPO. A larger powered study is underway to assess the impact of CPAP on intubation rate, length of inpatient stay and hospital mortality.

Comparative studies on platelet function and haemostasis in patients undergoing surgical trauma: effects of four intravenous fluids in patients undergoing hip replacement. A prospective double blind randomised study

E C CROWHURST, S J DAVIDSON, J GLENN, S HEPTINSTALL, W MADIRA, P A EVANS

Accident and Emergency Department, Leicester Royal Infirmary NHS Trust, Leicester LE1 $5 \mathrm{WW}$

Using an elective orthopaedic model of trauma we investigated the effects of four different intravenous fluids on platelet aggregation and measures of coagulation as well as bleeding time and postoperative blood loss This provided an effective and standardised degree of trauma and enabled pre-trauma measurements to be made without the confounding effect of factors such as sepsis, hypothermia and acidosis.

We studied 55 patients undergoing primary total hip arthroplasty. Two litres (as ATLS standard) of $4.5 \%$ albumin, or Gelofusine or Haemaccel or saline were given during the operation. Blood was taken and bleeding time performed immediately before start of surgery (PRE), at the end of surgery (POST) and two hours after the end of surgery (LAST). Platelet aggregation was determined in response to a variety of agonists.

Gelofusine and Haemaccel completely abolished aggregation in response to ristocetin at the POST $(\mathrm{p}<0.001$ and $\mathrm{p}=0.001)$ and LAST time points $(p=0.001$ and 0.006$)$. Albumin inhibited aggregation in response to collagen $)$ at POST $(p=0.004)$ and LAST time points $(\mathrm{p}=0.006)$

There were persistent increases in prothrombin $\mathrm{F} 1+2$ complex and thrombin/ antithrombin III complexes $(\mathrm{p}<0.0017$ and $\mathrm{p}<0.0013$ for all fluids) showing that the response to injury in our model was significant. Persistent reduction of fibrinogen and increase of INR was seen for all fluids $(\mathrm{p}<0.0146$ and $<0.0125$ respectively), and persistent reduction of factor XIII for the colloid fluids $(\mathrm{p}<0.0077)$. APTT and factor VIII activity only fell at the POST time point when colloids were used $(p<0.0105$ and $p<0.0166)$.

Bleeding time increased for all the colloid fluids $(\mathrm{p}<0.0324)$ at the POST time point, returning back to baseline by the LAST time point. There were no significant effects on postoperative blood loss. Plasma viscosity was persistently depressed only by saline and albu$\min (\mathrm{p}<0.0001)$.

Overall colloid fluids inhibit certain aspects of platelet function and the coagulation system. This may be clinically useful as trauma is associated with a pro-thrombotic state. 
Whole blood coagulation analysis of $40 \%$ haemodilution with resuscitation solutions

E V BRAZIL, D A PEACOCK, M HERON, T J COATS Academic Unit, Accident and Emergency Department, Royal London Hospital, Whitechapel, London E1 1BB

Introduction-Severely injured patients have altered haemostasis that may be compounded by the type of resuscitation fluid used. In vivo haemodilution in excess of $40 \%$ can occur during fluid resuscitation. The Sonoclot analyser measures the quality of a developing blood clot, including the rate of fibrin formation (RATE) and the time to reach maximum clot strength (PEAK).

Aim-To examine in vitro the effect of $40 \%$ haemodilution with various resuscitation fluids on whole blood coagulation by Sonoclot analysis.

Methods-Each of 10 volunteers had nine fresh blood samples taken from a free flowing upper limb vein and added to solution to make a $40 \%$ dilution. The solutions studied were $0.9 \%$ sodium chloride, Hartmann's, $5 \%$ dextrose, gelofusine, haemaccel, dextran, hydroxy-ethyl starch (HES) and albumin. One undiluted sample was taken as control.

Results-Rate and PEAK measurements for control and the various solutions are presented in table 6 .

Table 6

\begin{tabular}{lll}
\hline & PEAK (seconds) & RATE \\
\hline Control & 1172 & 20.7 \\
NaCl & 966 & 19 \\
Hartmann's & 1745 & $15.2^{\star}$ \\
Haemaccel & $897 \dagger$ & 17 \\
Gelofusine & $1979^{\star}$ & $11.5^{\star}$ \\
HES & $2353^{\star}$ & $8.5^{\star}$ \\
Albumin & 1703 & $10.4^{\star}$ \\
Dextose & $>2500 \ddagger$ & $3.4^{\star}$ \\
Dextran & $>2500 \ddagger$ & $3.5^{\star}$
\end{tabular}

${ }^{*} \mathrm{p}<0.008, \mathrm{tp}=0.0195$ Wilcoxon signed rank test, solution $v$ control; łno PEAK measurement possible.

Conclusions-The colloids gelofusine, HES, albumin and dextran all impair whole blood coagulation. In contrast haemaccel promotes coagulation. Unlike blood diluted with $0.9 \%$ sodium chloride, clot quality is reduced by haemodilution with $5 \%$ dextrose and Hartmann's.

What is the effect of reporting all emergency department radiographs?

J R BENGER, I D LYBURN

Emergency Department, Frenchay Hospital, Bristol BS16 1LE

Objective-To evaluate the effect of formal radiological reporting of emergency department (ED) radiographs on clinical practice and patient outcome.

Methods-All radiographs taken in a single ED over a six month period were prospectively studied simultaneously in both the emergency and radiology departments to detect discrepancies between the ED interpretation and final radiologist's report. Where a discrepancy was detected the patient was followed up to determine the source of the discrepancy, the correct interpretation and the clinical impact of the reporting process.

Results-During the study period, 19468 new patient attendances generated 11749 radiographic examinations. Discrepancies were detected in 175 patients $(0.9 \%$ of new attendances and $1.5 \%$ of radiographic examina- tions). Of these, 136 were subsequently shown to have been incorrectly interpreted in the $\mathrm{ED}$, with 40 patients undergoing a change in management as a result. In the remaining 39 the ED interpretation was judged to be correct, with 16 patients undergoing further investigations or visits to the ED to confirm this. Review of the discrepant cases suggests that some groups of ED radiographs (such as those interpreted by an ED consultant and certain peripheral limb films) may not require formal radiological reporting.

Conclusion-Radiological reporting of ED radiographs detects a small number of clinically important radiological abnormalities that would otherwise be overlooked, but also generates an appreciable proportion of false positive interpretations requiring further investigation. The adoption of a selective reporting policy may reduce the false positive rate and radiology workload without compromising patient care.

Emergency nurse practitioners in the UK-effectiveness and cost

I SAMMY, O GOODALL, J WINDLE

Accident and Emergency Department, Hope Hospital, Salford M6 8HD

Objectives-To assess the effectiveness, competence and costs of emergency nurse practitioners (ENPs) compared with SHOs in accident and emergency (A\&E)

Methods - A retrospective study of A\&E case notes, covering a six week period. A total of 643 study subjects and 1295 controls were included. Costs were calculated using hourly costs for both groups of clinicians as obtained from the Trust's finance department. These were related to rate of work of doctors and nurse practitioners. Costs of training and work generated per consultation are also discussed.

Results-Patients seen by ENPs and SHOs were comparable in terms of age and sex, but were significantly different with respect to triage category, time of attendance and anatomical site of injury/illness. Patients seen by nurse practitioners were seen quicker than those seen by SHOs. This difference was significant. There was no significant difference between the number of radiographs ordered by nurse practitioners and SHOs. The number of radiographs "misdiagnosed" in both groups was similar. The number of patients with misdiagnosed radiographs who required recall was also similar. SHOs were more likely to refer patients to inpatien teams. But the rate of admission for referred patients was similar for SHOs and nurse practitioners. Nurse practitioners were more likely to request senior advice than SHOs.The number of patients re-presenting for unbooked reviews was similar in both groups. Patients seen by SHOs were more likely to require admission than those seen by nurse practitioners. The cost of service of nurse practitioners was similar to that of SHOs. The costs of training of each group was also identified for discussion, but not quantified.

Conclusion-Nurse practitioners are capable of providing a safe and effective service for patients with less serious injuries. The cost of such a service is comparable with that of SHOs.

\section{Posters: Trauma (1)}

Views and needs of specialist registrars on research in accident and emergency medicine

A WALKER, T B HASSAN, A GRAY

General Infirmary at Leeds, Great George Street, Leeds, West Yorkshire LS1 3EX

Channelling the enthusiasm and needs of specialist registrars $(\mathrm{SpRs})$ in accident and emergency (A\&E) medicine to do research.The Faculty of A\&E Medicine encourages participation in research as part of the A\&E specialist registrar training programme. SpRs are required to document completed research projects, presentations, and publications. An informal review of $\mathrm{SpR}$ research in our region undertaken in 1999 revealed that $50 \%$ of SpRs had started research projects that they had failed to complete.

Objectives-A structured questionnaire was devised to identify A\&E SpRs' opinions and motivation for undertaking research.

Method-The questionnaires were sent to all $27 \mathrm{~A} \& \mathrm{E}$ SpRs in the region, and consisted of initial questions to assess the numbers of original publications and formal research training. The second part was a Likert-style questionnaire to identify $\mathrm{SpR}$ attitudes to undertaking research. Agreement with the statements made was defined as $5-7$, disagreement as $1-3$, and 4 was neutral.

Results-25 (93\%) questionnaires were completed satisfactorily. SpRs' reasons for carrying our research included; for personal development, to improve job prospects and to make them better A\&E consultants offering better advice to their trainees (median 6, range $4-7$ ). The major limitations to research were thought to be insufficient time (median 6 , range 2-7) and insufficient guidance (median 5 , range 2-6). Overall there was support for a regional research forum to provide expertise in research methodology, help coordinate projects, and advise on unrealistic projects (median 6, range 5-7). Trainees were keen to bring research ideas to a research forum (median 6, range 4-7). The trainees suggested that publication of at least one research project in a peer reviewed journal should be mandatory for an A\&E trainee (median 6 , range 1-7). There was support for either a weekly research commitment (median 5, range 2-7) or training with a 3-6 month secondment for a specific project (median 5 , range 1-7).

Conclusions - SpRs in A\&E medicine are motivated to undertake research. A regional research forum could help to meet their research activity needs and channel their enthusiasm.

Study comparing use of plain abdominal films among accident and emergency doctors of varying experience

RUSSELL MCLAUGHLIN

Nerutonabbey

Objectives-Determine whether appropriateness of request and documentation of findings varied with accident and emergency (A\&E) experience of referring doctors.

Methods-Over six weeks, a list of plain abdominal films (PAFs) requested by the A\&E department of Belfast City Hospital was obtained from the radiology department. Charts were reviewed by an $\mathrm{A} \& \mathrm{E} \mathrm{SpR}$ whereby radiological findings of the A\&E doctor were recorded and the appropriateness of the indication was determined using RCR 
guidelines. The doctors were grouped: group 1 (< 6 months full time A\&E department work), group 2 (6 months-1 year full time $\mathrm{A} \& \mathrm{E}$ department work), group 3 ( $>1$ year full time $\mathrm{A} \& \mathrm{E}$ department work), group 4 (1 year AED work part time equivalent-that is, GP). Results-Over six weeks 100 PAFs were ordered, representing $2 \%$ total attendance (5274). Fifty eight per cent were not indicated. Group 1 ordered 42 PAFs $-69 \%$ were not indicated and $48 \%$ had no documented interpretation. Group 2 ordered 35 PAFs$49 \%$ were not indicated and $43 \%$ had no documented interpretation. Group 3 ordered $14 \mathrm{PAF}-43 \%$ were not indicated and $29 \%$ had no documented interpretation. Group 4 ordered nine PAFs $-67 \%$ were not indicated and $33 \%$ had no documented interpretation. $\chi^{2}$ Testing using $10 \%$ probability showed significant difference between group 1 and groups 2,3 and 4 regarding appropriate radiographic ordering. Significant difference was not shown between groups 2, 3 and 4 . No significant difference was demonstrated between any groups regarding documentation of radiological findings.

Conclusions-There is statistically significant improvement in appropriate ordering of PAFs following six months full time A\&E department work. There is no such difference following six months but there is a perceived trend toward increasing appropriateness with experience. No significant improvement in documentation is shown but there is also perceived improved documentation with experience. These results strengthen the argument for staffing A\&E with doctors of six months $A \& E$ experience and greater, that is, increased senior shop floor work.

How well do accident and emergency departments resuscitate patients? A postal questionnaire to assess the views of burns and intensive therapy units

E C CROWHURST, N O'CONNOR, P A EVANS

Accident and Emergency Department, Leicester Royal Infirmary NHS Trust, Leicester LE1 $5 W W$

Background-Patients requiring transfer to burns units or intensive therapy units (ITUs) from the accident and emergency (A\&E) department should be resuscitated and adequately analgesed before transfer to the specialist unit.

Methods - All burns unit consultants and ITU consultants in the UK and Republic of Ireland were sent questionnaires on their assessment of $\mathrm{A} \& \mathrm{E}$ management prior to transfer. If inadequate, they were asked to specify all deficiencies that applied. Consultants were identified as those listed in the 1997 Directory of Emergency and Special Care Units.

Results-Response rates: burns survey. First capture January $199941 \%$. Second capture June 1999 14\%; overall response rate 55\%. ITU survey. First capture June 1999 39\%, second capture September 1999 16\%; overall response rate $55 \%$. Thirty per cent of burns consultants thought resuscitation was adequate ( $45 \%$ inadequate, $25 \%$ no answer), whereas $46 \%$ of ITU consultants thought it was adequate ( $37 \%$ inadequate, $17 \%$ no answer or not applicable). The order of commonest inadequacies are as follows. Burns unit: burn area assessment $(89 \%)$, too little iv fluid $(82 \%)$, burn depth assessment $(80 \%)$, analgesia not appropriate $(62 \%)$, other injury not identified $(60 \%)$, temperature of patient $(57.8 \%)$, too much iv fluid (53\%), inappropriate iv fluid (49\%), assessment of patient weight $(38 \%)$, other $(18 \%)$. ITU: too little iv fluid $(31 \%)$, temperature of patient $(25 \%)$, inadequate venous access (22\%), analgesia not appropriate $(19 \%)$, inappropriate fluid $(15 \%)$, poor documentation (13\%), assessment of patient weight $(10 \%)$, too much iv fluid $(9 \%)$, inadequate airway $(8 \%)$, other given little or wrong information $(8 \%)$.

Conclusions-Our survey suggests that individual specialties have different interpretations as to the adequacy of treatment. Closer liaison between these specialties is required to improve and standardise patient care.

Referral of paediatric accidental head injuries for intensive care

S S AHMAD ${ }^{\star}$, M KENNY $^{\star}, \mathrm{D}$ THOMPSON${ }^{\star \star}, \mathrm{M} \mathrm{J}$ PETERS ${ }^{\star}$

*Paediatric Intensive Care Unit and ${ }^{*}$ Department of Neurosurgery, Great Ormond Street Hospital for Children, London WC1N 3 FH

Introduction-Head injury is the most common cause of death at age 1-15. The RCS Working Party (1999) highlights the role of the emergency department (ED) and the need for neuroscience unit referral. Increasing numbers of children with acute head injury (AHI) are admitted to our paediatric intensive care unit (PICU) and therefore we undertook a retrospective study to determine the origin, timing and frequency of referrals.

\section{Table 7}

\begin{tabular}{llllll}
\hline 1995 & 1996 & 1997 & 1998 & 1999 & 2000 \\
\hline 10 & 20 & 28 & 33 & 46 & Est 65 \\
\hline
\end{tabular}

Methods-Retrospective review of retrieval database and admission books 1995 to May 2000 . Inclusion criteria were, a clear history of accidental trauma, same day referral and GCS of $\leqslant 8$.

Results - Of 173 patients admitted to our PICU, 13 were excluded as lacking a clear history of accidental trauma. This population was similar to other series with (median age 7 years range: 4 weeks-15 years), a male predominance $(66 \%)$, and pedestrian road traffic accidents being most common mechanism of injury $(50 \%, 87$ of 173), which accounted for the majority $(87 \%, 13$ of 15$)$ of the deaths. Craniotomy was rarely required (3\%, 5 of 173). Cervical spine and other injuries were rarely seen. Cases referred for PICU rose each year. Forty eight different EDs referred an average of three patients every five years. Eight one per cent of cases were referred in the eight hour period 1600-2400. Referrals rate in May to September is three times that in October to April, with peaks attached to bank holiday weekends. The median time between referral and PICU admission was 3.5 hours. The average distance from ED to ICU was 18.9 miles (tables 7 and 8).

Conclusion-AHI are clustered in summer EDs see these cases infrequently. Staff skilled in paediatric advanced airway and head injury management should be targeted for the early evening hours. The increased referral rate may reflect altered local PICU provision but is yet pathology not identified (8\%), next of kin

to plateau. Closer inspection of the mechanisms and nature of these injuries in addition to late follow up is planned.

Developing guidelines for paediatric head injury

P A YOUNGE

Emergency Department, Frenchay Hospital, Bristol BS16 1LE

Objective-To develop pragmatic evidence based paediatric head injury guidelines.

Method-A Medline search using OVID interface, evidence based web sites, references of references and regional experts was performed. Draft guidelines were drawn up and a prospective three month audit of current practice was performed. Guidelines and audit results were reviewed by a multi-disciplinary panel and further refinements made. Continuous three monthly audit cycles are ongoing. The principles upon which the guidelines were based are as follows:

1 Children with a reduced GCS should have urgent computed tomography

2 The presence of skull fracture is strongly predictive of intracranial lesions, however most children with skull fracture and GCS 15 do not have neurosurgical lesions.

3 Children over 2 with intracranial lesions, with or without a skull fracture manifest symptoms.

4 It is not practical to undertake computed tomography for all children with GCS 15 and skull fracture or symptoms. We suggest combining these predictors by using skull radiographs in children with persistent symptoms. If a fracture is discovered computed tomography should be arranged, otherwise children are admitted as necessary

5 Children under 2 are difficult to assess, may harbour occult intracranial injury and have a higher incidence of NAI. We recommend that they all undergo skull radiography and observation unless injury is trivial.

6 Other factors associated with intracranial lesions are focal signs, seizures, base of skull fracture, loss of consciousness $>5$ minutes and abnormal clotting. These features warrant computed tomography.

Audit demonstrated that our current practice already followed these principles with a slight overuse of skull radiography in those with trivial injury. Observation of children was occurring with most recovering within four hours.

Conclusion - By using the evidence, a multidisciplinary approach and repeating audit cycles we have developed a successful pragmatic set of paediatric head injury guidelines.

Haemorrhage into an arachnoid cyst-a serious complication of minor head trauma

KATIE DE, KATHLEEN BERRY

Birmingham

Background-Arachnoid cysts are intraarachnoidal cerebrospinal fluid collections that are usually asymptomatic, however they may become acutely symptomatic due to haemorrhage and cyst enlargement, which may result from minor head trauma. The

Table 8 AHI admission by time of day (\% of total admission)

\begin{tabular}{lclllll}
\hline & $00.01-40.00$ & $04.01-08.00$ & $08.01-12.00$ & $12.01-16.00$ & $16.01-20.00$ & $20.01-24.00$ \\
\hline ICU referral & 2 & 0 & 3 & 15 & 46 & 35 \\
ICU admission & 39 & 1 & 0.6 & 8 & 16 & 33 \\
\hline
\end{tabular}


range of symptoms is wide and many are "soft" signs. Diagnosis is important as those causing mass effect require surgery.

Methods - We report a case of a child presenting with localised headaches following minor head trauma. Computed tomography demonstrated an arachnoid cyst with evidence of haemorrhage and mass effect, which required surgical intervention. Other cases presenting to our hospital or reported in the literature are reviewed with respect to presenting symptoms and signs.

Results-Localised headaches, behavioural or cognitive changes and ataxia are more commonly associated with this pathology than nausea, vomiting, visual disturbances or seizures in the cases we reviewed.

Conclusion-This range of symptomatology following minor head trauma may warrant computed tomography when other criteria for this investigation are not met.

\section{Traumatic spine fractures in England} and Wales

R S SIEBER, M CLANCY, F LECKY, M WOODFORD, D W YATES

The Trauma Audit \& Research Network (TARN), Clinical Sciences Building, Hope Hospital, Stott Lane, Salford M6 8HD

Objectives-The Trauma Audit \& Research Network (TARN) database was analysed to ascertain spine fracture prevalence, distribution and mechanism of injury.

Method - Retrospective analyses were done for patients with traumatic spine fracture from a dataset of 110129 patients collected prospectively by 94 hospital between 1989 and 1999 . A spine fracture was defined as a damage to a single vertebral bone, including burst, anterior or lateral compression, facet, pedicle, laminar or dens fractures with exclusion of spinous process and transverse process fractures.

Results -9374 patients or $8.5 \%$ of database patients were registered with at least one spine fracture. The database prevalence for the three spine levels is $1.8 \%$ for cervical fractures (1979), 2.9\% for thoracic (3.202) and 3.8\% for lumbar (4.193), leading to a three quarter dominance of thoracic and lumbar fractures. The median ISS was 10 in the cervical section, 8 in the thoracic and 6 in the lumbar spine. The median database ISS was 10 . The mean age was 45 years. On the database an equal proportion of RTA victims (3.372/ $36.824)$ and fall victim $(5.104 / 52.745)$ had a spine fracture. However, falls were the most frequent injury mechanism (54.5\%/5104), divided in $22 \%<2 \mathrm{~m}$ and $32 \%>2 \mathrm{~m}$. RTA victims accounted for $36 \%$ (3.372). Altogether 709 patients had multilevel fractures $(7.6 \%$ of

Table 9

\begin{tabular}{lll}
\hline & Phase one & Phase two \\
\hline Mean waiting time to be seen by the A\&E doctor & 17 minutes & 13 minutes \\
& $(1-57$ minutes $)$ & (1-48 minutes) \\
Mean time to remove spinal board & 31 minutes & (3-22 minutes) \\
& (median 10 minutes) & 8 minutes \\
Mean time on the spinal board when removed after the primary & 29 minutes & (3-45 minutes) \\
survey only & 147 minutes & - \\
Mean time on the spinal board when removed after the primary & (60-235 minutes) \\
survey and radiographs & \multicolumn{2}{l}{}
\end{tabular}

all fractures patients). These had mainly fractures within thoracic and lumbar segments $(473 / 66.7 \%)$. Second are cervico-thoracic fractures $(153 / 21.6 \%)$.

Conclusions-Unlike other spine injury reports, we identified falls as the main cause of spine fractures even if $<2 \mathrm{~m}$. We documented a large burden of thoraco-lumbar fractures, which is frequently underestimated. These results are gathered from a broad mix of hospital and patients and are therefore representative. Prospective data collection of trauma patients is essential for the ongoing analysis of trauma pattern and the subsequent evolution of trauma care.

\section{Spinal boards in accident and} emergency-their use and abuse

K MURALI

Accident and Emergency Department, City Hospital, Birmingham B187QH

Introduction-The spinal board is a transport device used predominantly in the pre-hospital setting. Prolonged retention of an injured patient on a spinal board in the accident and emergency (A\&E) department can potentially lead to complications.

Aim - To determine the pattern of use of spinal boards in a busy inner city A\&E department, draw up a protocol and reassess the usage pattern after implementation of the protocol.

Methods - This study is a prospective longitudinal study done in two phases. Data were collected using a proforma in both the phases. Phase two was after implementation of an agreed protocol.

Results-The results are shown in table 9.

Conclusion-Significant reduction in patient time on the spinal board was achieved after the introduction of a protocol. More importantly, a perceptible change in the attitude to the use of spinal board has been achieved. But continuing education and monitoring is emphasised to maintain the positive change.
The use of ultrasound in the initial assessment of blunt diaphragm rupture

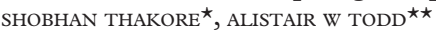
*Ninewells Hospital, Dundee DD1 9SY, **Raigmore Hospital, Inverness

Rupture of the diaphragm occurs in approximately $5 \%$ of cases of blunt abdominal trauma requiring laparotomy, and is considered a marker of severity. Late diagnosis is associated with herniation and possibly strangulation of abdominal contents. It is therefore important to detect the injury with early investigations. Chest radiographs and and computed tomography are commonly used but there are few reports describing the use of ultrasound. We have collected six cases showing clinical situations in which ultrasound may be useful and one that demonstrates a potentially significant pitfall.

Cases were collected at Raigmore Hospital in Inverness (table 10). Ultrasound preceded computed tomography in all cases where both investigations were performed. Four cases did not undergo computed tomography, with the decision for operative intervention based on the ultrasound report, chest radiographs and clinical characteristics. The only false negative ultrasound and CT scans were performed on the same patient. The ultrasound showed the left hemidiaphragm to be moving with respiration and it was therefore felt to be intact. We suggest that this sign depends on spontaneous respiration, where diaphragm movement is produced by its own contraction. Positive pressure ventilation causes movement of the diaphragm and inferior structures by expanding the overlying lung. This can lead to the false impression of an intact hemidiaphragm.

In diaphragm rupture, chest radiographs can be helpful, but are diagnostic in only $27-64 \%$ of left and $17 \%$ of right sided injuries. Computed tomography is frequently used, however reports show wide ranging sensitivities. Ultrasound is used in the initial assessment of blunt abdominal trauma with sensitivities similar to computed tomography. It is portable and relatively rapid and hence can be used in the resuscitation room while

Table 10 Results of initial investigations

\begin{tabular}{|c|c|c|c|c|}
\hline Case & Chest radiograph & Ultrasound scan & $C T$ & Surgery \\
\hline $\mathrm{A}$ & Raised RHD & High liver with fluid visible above and below & Not done & Ruptured RHD with liver herniation \\
\hline B & Indistinct LHD & LHD completely disrupted & Not done & $\begin{array}{l}\text { Ruptured LHD with herniation of } \\
\text { stomach, colon and omentum }\end{array}$ \\
\hline $\mathrm{C}$ & $\begin{array}{l}\text { Extensive right haemothorax, } \\
\text { multiple rib \#s, raised RHD }\end{array}$ & $\begin{array}{l}\text { RHD and liver elevated. Rupture "not } \\
\text { excluded" }\end{array}$ & $\begin{array}{l}\text { RHD rupture with liver } \\
\text { herniation }\end{array}$ & $\begin{array}{l}\text { RHD rupture with herniation of liver and } \\
\text { liver laceration }\end{array}$ \\
\hline $\mathrm{D}$ & $\begin{array}{l}\text { Right pneumothorax and } \\
\text { indistinct RHD }\end{array}$ & $\begin{array}{l}\text { Poor views of RHD. Dome of RHD } \\
\text { unsighted with considerable free fluid in } \\
\text { Morrison's pouch }\end{array}$ & $\begin{array}{l}\text { Liver laceration, elevated } \\
\text { RHD suggesting rupture }\end{array}$ & RHD rupture, liver and spleen laceration \\
\hline $\mathrm{E}$ & Indistinct LHD & $\begin{array}{l}\text { Poor views but LHD seen to move with } \\
\text { respiration }\end{array}$ & $\begin{array}{l}\text { Poor views but no evidence } \\
\text { of rupture }\end{array}$ & $\begin{array}{l}\text { LHD rupture at operation } 7 \text { days after } \\
\text { admission }\end{array}$ \\
\hline $\mathrm{F}$ & $\begin{array}{l}\text { Right haemo-pneumothorax, } \\
\text { \# ribs }\end{array}$ & RHD rupture & Not done & $\begin{array}{l}\text { RHD rupture with liver and greater } \\
\text { omentum herniation and liver laceration }\end{array}$ \\
\hline G & $\begin{array}{l}\text { Loss of definition of RHD and } \\
\text { right cardiac border, raised } \\
\text { RHD }\end{array}$ & $\begin{array}{l}\text { Liver elevated, no diaphragm seen } \\
\text { intervening liver and lung, liver failed to } \\
\text { move with respiration }\end{array}$ & Not done & RHD rupture with liver herniation \\
\hline
\end{tabular}

LHD, left hemidiaphragm; RHD, right hemidiaphragm. 
potentially life saving interventions are on going. This series supports the role of ultrasound in the diagnosis of blunt diaphragmatic rupture when it is suspected on clinical grounds or after the initial chest radiograph. Potential pitfalls should be borne in mind and the investigation performed by experienced operators to maximise sensitivity. An ultrasound scan supporting the diagnosis of diaphragmatic rupture can negate the need for computed tomography and hence reduce any potential delay to operation.

\section{Traumatic haemarthrosis of the knee} M A ANSARI

City Hospital NHS Trust, Dudley Road, Birmingham

Objective-To evaluate the injuries sustained following haemarthrosis of the knee in a relatively younger population and to assess the need of doing culture of aspirated blood.

Pateint and methods-Notes of 510 patients were retrospectively studied to record age, sex, mechanism of injury final diagnosis and management. Reports of culture of aspirated blood were collected from the department of pathology.

Results-Most cases were of 20-30 years of age group and the male to female ratio was $4: 1$. Slipping on the floor, pavement or stairs was the major cause of haemarthrosis. Sports injuries accounted for $38 \%$ haemarthrosis. On final discharge, $40 \%$ patients had idopathic haemarthrosis, followed by anterior cruciate ligament damage in $15 \%$ and meniscal injury in $12 \%$ of patients and posterior cruciate injury in 3\%. All cases were attributable to trauma. There were only eight isolates from 510 aspirates, five $\alpha$ haemolytic streptococci, two coryne bacterium and one mixed skin flora were cultured. All these were thought to be non-pathogenic.

Conclusions-Sports injuries are a major cause of haemarthrosis in a young population. Culture of aspirated blood showed no growth and thus seemed to be a waste of resources and were totally unnecessary.

\section{Poisoning}

"Herbal highs"-natural and safe, or nasty and scary?

CHARLOTTE DOUGHTY, ALISON WALKER Hull Royal Infirmary, Anlaby Road, Hull, East Yorkshire HU3 $2 \mathfrak{F Z}$

Background-Demand for herbal based alternatives to recreational drugs is on the increase. These are widely available both via the internet and at many music festivals. They are generally assumed by those using them, to be a safe alternative to taking illegal recreational drugs. Several studies have highlighted problems with these drugs.

Methods-Several possible adverse reactions to these substances occurred in patients who attended V'98 and Leeds '99 music festivals. Forensics laboratory analysis was carried out on seven herbal drugs sold on site. Mass spectrometry was undertaken to ascertain whether they contained illicit drugs, caffeine or ephedrine. The analysis was carried out with advice from the regional drug squad and with the help of the Forensic Science Service. The literature was searched to determine whether the herbal constituents were as safe as alleged. Results-The literature search identified data on eight different herbal constituents. These included an anxiolytic (Kava) more effective than benzodiazepines. In addition Sweetflag, was also identified as a potentially carcinogenic substance. The results of the forensic analysis revealed that two of the seven capsules contained significant levels of caffeine, and a further two contained caffeine and ephedrine. No significant levels of illicit drugs were identified

Conclusions-Accident and emergency staff should include the use of herbal medicines as part of a patient's drug history. A patient's clinical condition may be significantly influenced by the use of these substances.

\section{$\gamma$ Hydroxybutyric acid: a new case of drug} misuse

S H BOYCE, K PADGHAM, L D MILLER, J STEVENSON Accident and Emergency Department, Crosshouse Hospital, Kilmarnock.

The use of recreational drugs in society is becoming a widespread problem increasing the workload of all the emergency services. $\gamma$ Hydroxybutyric acid is one of these, a drug used primarily for its euphoric effect. Toxic effects of ingestion include bradycardia, slow respiration or apnoea, coma and death. We present seven cases, all of which had consumed $\gamma$ hydroxybutyric acid either alone or in conjunction with other drugs and alcohol. The presentation, clinical features and managemen of these cases is described. All health care personnel involved in the emergency setting need to know of its existence, toxic effects and initial management with particular reference to airway control and possible assisted ventilation.

Under-recording of deaths due to drug misuse?

LUCINDA B EBDON, CAROLYN A MEREDITH, JOHN A HENRY

Academic Department of Accident and Emergency Medicine, St Mary's Hospital, South Wharf Road, London W2 1NY

Drug misuse is an increasing cause of morbidity and mortality in Britain. The curren official figure of 1800 deaths per year due to drug misuse is based on death certificates and coroners' reports. We suspected that these figures are an underestimate, and carried out a hospital-based survey of all the deaths occurring in an inner city hospital over a one year period (1 January-31 December 1999). The records of all patients under 70 years of age who died in the hospital were examined to determine whether the patient had been an illicit drug user, and the course of illness and cause of death as recorded on the death certificate were noted. Three independen doctors reviewed each case to determine whether the cause of death could be attributed to drug misuse.

There was a total of 955 deaths. Of these seven were recorded as due to drug misuse and reported to HM Coroner. Of the remain ing 683 available sets of notes, 17 had a history of drug misuse. In 12 cases these were reported to the coroner, but in none of these cases was drug misuse recorded as implicated in the death. Of the remaining five, drug mis use was not mentioned in any of the death certificates. The three independent doctors attributed death to drug misuse in 6 of the 17 cases with a high concordance.

Deaths due to drug misuse are probably under-reported. Further work is needed to establish its extent. Drug misuse should form a part of history taking and be recorded in the interests of the patient to ensure a correc diagnosis. This will also lead to better record- ing and reporting of the consequences of illicit drug use.

Detection of alcohol misuse: attitudes of junior doctors

J S HUNTLEY, C BLAIN, R TOUQUET

Department of Accident and Emergency Medicine, St Mary's Hospital NHS Trust, Praed Street, London W2 1NY

Introduction-Alcohol misuse is a major burden on the emergency system. Despite the developing the one minute Paddington Alcohol Test (PAT), the effectiveness of interventions and the possibility of medicolegal consequences, the detection rate of misuse remains low. We sought to assess $\mathrm{SHO}$ attitudes (one possible problem) to PAT usage and the detection of alcohol misuse.

Methods-A questionnaire was given to St Mary's accident and emergency (A\&E) SHOs, in their last month of employment. Questions pertained to the overall epidemiology of PAT possibility/positivity, attitudes to detecting/referring alcohol misuse, and self evaluation of PAT positivity/misuse. Currently, data are available for three serial teams $(\mathrm{n}=13,12,12$; total $=37$ ).

Results-SHOs varied widely in their prevalence estimations of PAT possible complaints, but were unanimous on the importance of early detection, that detection was their remit, and that treatment could be successful. The majority thought $A \& E$ to be appropriate for PATs (35 of 37), that drinking alcohol was part of our culture (32 of 37), but did no think that it should be negligent to miss a PAT possible condition (30 of 36). SHOs (12 of 13) found audit increased awareness of alcohol as a root cause; 11 of 13 thought they identified more PAT positive patients. Lack of time was identified as a limiting factor. The fact that 16 of 37 SHOs thought themselves PAT positive, with 25 of 37 admitting alcohol misuse $\geqslant 1 /$ month, is an indication of the extent to which alcohol (mis)use is an accepted part of our culture.

Conclusions-SHOs are committed to the principles underlying the PAT and the importance of early detection of alcohol misuse

Transatlantic differences in the management of alcohol intoxication

SENTHI SALLATURAY, JOHN A HENRY

Department of Accident and Emergency, St Mary's Hospital, South Wharf Road, London W2 $1 N Y$

The large cultural differences between Britain and the Unites States of America led us to compare policies towards violent or intoxicated patients in four hospitals in New York and four hospitals in London. Each hospital was visited and answers to a 15-point questionnaire were obtained from a senior staff member. The four New York hospitals had similar policies. In each, intoxicated patients were restrained to prevent them leaving the department, if necessary by applying restraint bandages until they were deemed to have zero alcohol levels as judged either by breath alcohol levels or by calculating the decline from an initial blood alcohol level. The four London hospitals were similar in that each attempted to exclude potentially serious conditions before allowing the patient to leave when clinically judged to be in no danger of immediate harm. Blood or breath alcohol levels are not routinely measured. In contrast with New York, violent or disruptive patients 
were usually ejected from the department. This tale of two cities demonstrates how widely differing approaches may be used towards the same problem. The New York approach appears to be a defensive policy based on minimising the risk of subsequent legislation against the potential consequences of an alcohol intoxicated patient being allowed to leave. In Britain there seems to be a policy of balancing the duty of care towards an intoxicated patient with the duty of care towards other patients in the department, so that a seriously disruptive patient is ejected even though intoxicated.

An in vitro assessment of the mechanism of adverse reactions to pharmaceutical acetylcysteine

RAJ BANERJEE, PHILIP DARCY, JOHN A HENRY

Department of Accident and Emergency, St Mary's Hospital, South Wharf Road, London W2 1 NY

Background-Paracetamol overdose is common, leading to 30000 hospital admissions and 345 deaths each year. Acetylcysteine (AC) will prevent toxicity if given early enough after overdose. However, its administration may be complicated by anaphylactoid reactions. Parvolex is a commercial preparation of AC for intravenous administration that contains AC $200 \mathrm{mg} / \mathrm{ml}$ together with Na-EDTA $33 \mathrm{mg} / \mathrm{ml}$ as a stabiliser. As part of a research programme into the mechanism of toxicity of AC we have examined its effects in rat mesentery mast cells. Our objective was to determine whether Na-EDTA contributed to the toxicity of the intravenous preparation.

Methods-Rat mesentery was isolated and treated with various concentrations of AC, Na-EDTA and Parvolex. The mesentery was then placed on a slide, stained, dehydrated and fixed. Cells were examined under blinded conditions from a video record to determine whether they were intact or degranulatedthat is, whether they showed disruption of histamine granules. The extent of disruption was calculated as a percentage of that observed at the highest dose of AC administered.

Results-EDTA showed minimal effect on mast cell degranulation, with a mean degranulation of $7 \%$ (range $6-9 \%$ ) at doses $0-1290$ $\mathrm{mM}$. AC showed a dose dependent increase in mast cell degranulation ranging from $20 \%$ at $10 \mathrm{mM}$ to $100 \%$ degranulation at $80 \mathrm{mM}$. Parvolex also showed a dose dependent effect on mast cell degranulation ranging from $15 \%$ at $10 \mathrm{mM}$ to $100 \%$ at $80 \mathrm{mM}$. Our findings showed that AC had a dose dependent, and therefore, anaphylactoid effect on mast cells, while Na-EDTA had no such effect, either alone or when formulated with AC. A change in formulation is unlikely to affect the severity of reactions, but our results and clinical experience suggest that a lower initial dose might reduce the severity of the reactions, which are dose dependent.

\section{Compliance of activated charcoal}

S K SHUBBER, F DUNN, L A MCKINNEY, J STEELE

Altnagelvin Area Hospital, Londonderry BT47 1SB

Objective-To assess the compliance of activated charcoal in adults and children.

Design-A questionnaire was sent out to one consultant in each of the 260 accident and emergency (A\&E) departments nationwide in the United Kingdom and the Republic of Ireland as per BAEM directory 1999/2000. The questionnaire asked firstly whether compli- ance of activated charcoal was a major problem in adults and/or children and secondly what proportion of the prescribed charcoal was ingested on average by the patients both in adults and children respectively. It also looked at the commercial types of activated charcoal dispensed in the departments.

Results-131 (50\%) departments responded to the questionnaire. Only $40 \%$ felt that compliance of activated charcoal was a major problem in adults compared with $76.2 \%$ who felt compliance was a major problem in children. It was perceived that $68.82 \%$ of the prescribed activated charcoal would be swallowed in adults compared with $39.7 \%$ in children. Vomiting was perceived to be next most important problem after compliance.

Conclusion-Compliance of activated charcoa is perceived to be greater problem in children than in adults.

\section{Poison information in the accident and} emergency department

S K SHUBBER, F DUNN, L A MCKINNEY, J STEELE Accident and Emergency Department, Altnagelvin Hospital, Londerry BT47 1SB

Objective - To assess how accident and emergency (A\&E) departments access poison information.

Method-A questionnaire was sent out to each consultant led A\&E department in UK and Ireland as seen in the BAEM directory 1999/ 2000. The questionnaire asked how poison information was accessed giving three main options, phone, Internet Toxibase and previous printed sheets.

Results - 260 consultants were sent a questionnaire, 130 replied, of these $11(8.4 \%)$ were departments seeing less 25000 new patients a year, $55(42 \%)$ were seeing between 25000 $50000,48(36.9 \%) 50000-75000$ and 16 $(12.3 \%)$ over 75000 . Fifty five departments used only the phone to access the information though eight $(14.5 \%)$ had plans to install the Internet Toxibase. Printed sheets were used in $14(10.7 \%)$ but only one $(0.7 \%)$ department used them on their own. The Interne Toxibase was used in $67(51.5 \%)$ of the departments in which 31 (46\%) department still used a phone.

Conclusion-Approximately 63 (48.4\%) of the departments still do not have Internet Toxibase installed.

Can a CD-ROM teaching programme improve the confidence of accident and emergency SHOs in assessing deliberate self harm patients?

ALISON WALKER, JANE BRENCHLEY

General Infirmary at Leeds, Great George Street, Leeds, West Yorkshire LS1 3EX

Background-Studies have shown that the assessment of deliberate self harm patients in the accident and emergency (A\&E) department is often inadequate. Many A\&E SHOs have little training in the assessment of these patients. Such patients can present difficultie in both assessment and management and frequently present "out of hours" when more senior advice may not be available within the department.

Methods-A CD-ROM was produced covering topics on deliberate self harm assessment including basic history taking, mental state examination, assessment of risk, the Menta Health Act, and management of deliberate self harm patients. Multiple video segments sum marise the assessment of a patient who had allegedly taken an overdose and presented to an $\mathrm{A} \& \mathrm{E}$ department, and the trainee is guided through the management of the patient. Baseline knowledge and confidence in assessment were recorded using Likert-style questionnaires. Confidence was defined as a score of 5-7. After completing the CD-ROM the trainees repeated the questionnaires and a further assessment of the value of the CD-ROM Results-14 SHOs completed the study. The pre-CD-ROM assessment showed reasonable levels of confidence in the assessment of deliberate self harm cases (median 5, range 3-6) but low confidence levels in the application of the Mental Health Act (median 3, range 1-4). Following the CD-ROM $79 \%$ of SHOs felt more confident in the assessment of these patients (median 5, range 4-7) and all felt more confident applying the Mental Health Act (median 5, range 2-6) an effect that was sustained over the following three months. The SHOs also assessed the usefulness of the CD-ROM as a learning tool and rated it highly compared with other teaching methods. They found it easy to use and a helpful educational tool, and recommended its use in the teaching of deliberate self harm assessment for future trainees.

Conclusions - The majority of trainees found the CD-ROM format to be preferable to other educational methods for this subject.

Does having the algorithm in front of you make a difference?

MARK G JENKINS

Ulster Hospital, Belfast

Aim - To assess the effect on simulated paediatric resuscitation, if the algorithm is in front of the operator.

Subjects-10 senior house officers (SHO), six with six months accident and emergency $(A \& E)$ experience and all with no paediatric experience or courses.

Methods-Three scenarios involving acute paediatric emergencies were simulated. Each scenario had key points. Each doctor was taken through the scenario twice. On the second occasion the algorithm was placed in front of the SHO. The algorithms were similar to APLS guidelines and had been collated into a flip chart.

Results-All SHOs improved markedly with the copy of the algorithm in front of them. In particular choice of drug and drug dose were correct.

Conclusion-Algorithms simple and readily accessible improve the quality of simulated paediatric resuscitation. For departments with paediatric attendances such algorithms could result in better outcomes until definitive help and care arrive.

Audit of antibiotic usage in a district accident and emergency department: before and after introduction of guidelines

O O JIBUIKE ${ }^{\star}$, ROGERS SAGE ${ }^{\star \star}$, BARBARA BAIRD ${ }^{\star \star}$, MICHAEL IMANA ${ }^{\star \star}$

*Accident and Emergency Medicine University Hospital of Wales, Cardiff, ${ }^{\star}$ Basildon Hospital, Basildon, Essex

Objective-To evaluate the effectiveness of antibiotic guidelines in an accident and emergency (A\&E) department, three months after their introduction.

Methods-Patients receiving antibiotics were traced on computer, October 1998 prior to introduction and January 1999. Antibiotic regimens used were located in the $\mathrm{A} \& \mathrm{E}$ records-choice of drug, dose, frequency, and 


\begin{tabular}{|c|c|c|c|c|}
\hline \multirow[b]{2}{*}{ Clinical condition } & \multicolumn{2}{|l|}{ October $1998(n=224)$} & \multicolumn{2}{|l|}{ fanuary $1999(n=221)$} \\
\hline & $\begin{array}{l}\text { Total number of antibiotic } \\
\text { prescriptions }\end{array}$ & $\begin{array}{l}\text { Number with appropriate } \\
\text { antibiotics, dose, frequency and } \\
\text { duration }(\%)\end{array}$ & $\begin{array}{l}\text { Total number of antibiotic } \\
\text { prescriptions }\end{array}$ & $\begin{array}{l}\text { Number with appropriate } \\
\text { antibiotics, dose, frequency and } \\
\text { duration (\%) }\end{array}$ \\
\hline Laceration & 14 & $3(21)$ & 25 & $9(36)$ \\
\hline Bites & 18 & $1(6)$ & 43 & $18(42)$ \\
\hline Cellulites & 30 & $2(7)$ & 14 & $2(14)$ \\
\hline Tonsillitis & 10 & $1(10)$ & 18 & $2(11)$ \\
\hline Chest infection/pneumonia & 38 & $6(16)$ & 37 & $6(16)$ \\
\hline Otitis media & 13 & $4(31)$ & 27 & $8(30)$ \\
\hline
\end{tabular}

$0.001<\mathrm{p}<0.01$.

p Value is very significantly less than 0.05 at $95 \%$ confidence limits.

duration of course for various conditions were noted. Changed prescribing habits were evaluated in the re-audit by the number of patients receiving entirely appropriate regimens as stipulated in the guideline.

Results-The results are shown in table 11 . For discussion purposes we subdivided the conditions into two groups: (1) skin and subcutaneous conditions. Correct prescribing improved for lacerations and bites, but not in treating cellulitis. (2) Throat, ear, chest conditions. Correct prescribing improved in real tonsillitis. There was little change in chest infection.

Discussion- $3.6 \%$ to $4 \%$ of our A\&E attendances received antibiotics- 1 per 26 attendances on average. Individually, the guideline changed the prescribing habits of $\mathrm{A} \& \mathrm{E}$ doctors to soft tissue conditions. Overall, there was statistically significant improvement in the appropriateness of prescriptions $(\mathrm{p}<0.01)\left(\chi^{2}\right.$ test of significance).

Conclusion-Three months after introduction, overall, our antibiotic guidelines effectively improved practice significantly. The problem, though, is with antibiotic course duration, where our prescribers seem uncomfortable with five days

\section{$\underline{\text { Acute medicine }}$}

Pulse oximeter waveforms in healthy humans

P M MIDDLETON, A J RETTER, J A HENRY

Academic Department of Accident and Emergency Medicine, St Mary's Hospital, South Wharf Road, London W2 1NY

Variations in pulse oximeter waveforms (POW) may be used to provide a non-invasive surrogate of the intra-arterial waveform. This potentially represents a readily accessible measure of cardiovascular status. Before the investigation of patients with different disease states, we examined the effects of age, blood pressure and smoking on waveform patterns. These factors are known to decrease arterial compliance, increasing peripheral wave reflection and altering the contour of the pressure waveform.

Supine recordings were taken from 185 healthy volunteers, recorded on Micromedical pulse software and analysed on a custom Matlab program. Pulse oximeter probes were placed on index and middle fingers of the left hand. Factors known to affect peripheral arterial compliance were recorded. Blood pressure was measured using a Propaq monitor. The waveform patterns were categorised into four distinct classes, similar to those described by Murgo and Nichols for intra-arterial pressure waveforms. Wave classification was compared with age and systolic blood pressure using ANOVA, and with smoking status using $\chi^{2}$ analysis. $\kappa$ Analysis gave a measure of agreement between index and middle fingers of 0.894 $(p<0.001)$. Post-hoc ANOVA revealed that there was a significant relation between waveform class and age $(\mathrm{p}<0.001)$, blood pressure $(\mathrm{p}<0.001)$, and smoking status $(\mathrm{p}=0.021)$.

These results show that POW from index and middle fingers can be considered as identical. Waveform classification varies with age, blood pressure and smoking. These effects may represent changes in the peripheral arterial system resulting in altered wave reflection. We have shown that POW produces reproducible patterns. Further research in this area may lead to the use of this technique as a measure of peripheral vascular responsiveness, in the diagnostic evaluation of acute disease.

Accidental hypothermia and the systemic inflammatory response to rewarming

J J MCINERNEY, W MADIRA, T DAVIES, A B BREAKELL, P A EVANS

Accident and Emergency, The Leicester Royal Infirmary, Infirmary Close, Leicester LE1 $5 \mathrm{WW}$

Introduction - The mortality rate from moderate accidental hypothermia (core temperature $<32^{\circ} \mathrm{C}$ ) is in excess of $50 \%$. Previous study has revealed significant $\mathrm{pH}$ related alterations in divalent cations and parathyroid hormone (PTH) during rewarming. The primary aim of this study was to determine the effect of rewarming on tumour necrosis factor $\alpha$ $(\mathrm{TNF} \alpha)$ and interleukin 6 (IL6). The secondary aim was to determine the relation of IL6 to the $\mathrm{PTH} /$ ionised calcium axis.

Methods - Eight patients, four men and four women, age 45 to 85 years (mean age 74.3 ), admitted with accidental hypothermia were included in the study. Patients were rewarmed with dry warm blankets and fluid replaced by crystalloid at $40^{\circ} \mathrm{C}$. Blood for serum $\mathrm{TNF} \alpha$, serum IL6, ionised calcium $\left(\mathrm{Ca}^{2+}\right)$ and serum PTH was collected at presentation, during rewarming, and at 24 hours.

Results-Four patients were admitted with mild $\left(32-35^{\circ} \mathrm{C}\right)$ and four with moderate $(28$ $32^{\circ} \mathrm{C}$ ) hypothermia. All patients responded to rewarming, with the initial mean rate rise in core temperature $0.78^{\circ} \mathrm{C} / \mathrm{h}$. There was a negative correlation between serum $\mathrm{TNF} \alpha$ and increasing temperature in all patients during rewarming ( $r=0.63, \mathrm{p}=0.0008)$, while IL6 and PTH showed a similar though non-significant trend $(r=0.18, \mathrm{p}=0.18$, and $r=0.22, \mathrm{p}=0.14$ respectively). Comparison of IL6 to $\mathrm{PTH}$ showed a positive correlation $(r=0.68$, $\mathrm{p}=0.0001)$. IL6 and PTH correlated positively $(r=0.775, \mathrm{p}=0.002$ and $r=0.72$, $\mathrm{p}=0.005)$ and negatively $(r=0.7, \mathrm{p}=0.004$ and $r=0.71, \mathrm{p}=0.004)$ with $\mathrm{Ca}^{2+}$ in moderate and mild hypothermia respectively.

Conclusion-Rewarming is associated with decreasing serum levels of the cytokines $\mathrm{TNF} \alpha$ and IL6. Poor outcome-that is, survival $<7$ days, was associated with age $(\geqslant 84$ years), presentation temperature $\left(<32^{\circ} \mathrm{C}\right)$, and non-physiological correlation between IL6, PTH, and $\mathrm{Ca}^{2+}$.

\section{Osteoporosis risk factors associated with} fractured necks of femur

C TOVEY, T LECKIE

Accident and Emergency Department, Hope Hospital, Salford M6 $8 H D$

Introduction-A recent report from the Royal College of Physicians (RCP) Osteoporosis: Clinical Guidelines for Prevention and Treatment represents the first definitive, evidence-based guide to managing the disease. The management of osteoporosis can be complex but the Primary Care Rheumatology Society recommend a minimum of activity that all practices should be considering. The guidelines state that as a minimum those patients receiving osteoporosis prophylaxis should include: (a) previous osteoporotic fracture; (b) early menopause (age 45 years or less); (c) patients taking prednisolone greater than $7.5 \mathrm{mg}$ daily for three months over age 50 years; (d) nursing home elderly should be on calcium and vitamin $\mathrm{D}$ tablets. The aim of this study is to look at 100 consecutive patients attending accident and emergency (A\&E) with fractured necks of femur and to determine whether they have risk factors for osteoporosis and whether they are taking osteoporosis prophylaxis.

Results-Up until 1 April we have the results of 51 patients and it is clear that few patients take osteoporosis prophylaxis despite risk factors. Twenty one patients had had a previous osteoporotic fracture and only three were taking prophylaxis. Eleven patients had early menopause (or hysteretomy) before the age of 45 (four of these patients also had a previous osteoporosis fracture, none of whom were taking osteoporosis prophylaxis). A number of patients were also residents of nursing homes.

Conclusion-There is very little point in the Department of Health commissioning the osteoporosis report by the RCP if their advice is not implemented. Orthopaedic staff should be aware of the guidelines and patients with osteoporotic fractures assessed for osteoporosis prophylaxis before discharge from hospital. A\&E should perhaps notify GPs that their patients have sustained an osteoporotic fracture and should be considered for osteoporosis prophylaxis. The osteoporosis risk in daughters of elderly patients should also be considered. The RCP report recommends that primary care take a case-finding approach to osteoporosis using bone density measurement as a cost effective tool for identifying individuals at high risk of fracture. 
Meningococcal disease in accident and emergency: characteristics and management. Can diagnosis and care be improved?

D R H BECKER, T A CHANDLER, P A EVANS Leicester Royal Infirmary, Infirmary Square, Leicester, LE1 5WW

Objectives-(1) To identify the sensitivity of the characteristics of meningococcal disease at the time of presentation in accident and emergency (A\&E) to assess their diagnostic values. (2) To evaluate the quality of current management in A\&E.

Methods-A retrospective analysis of the notes of patients identified as having had meningococcal disease who came through A\&E over a 21 month period.

Results - 60 casenotes were available $(88 \%)$; results refer to where information was recorded. Twenty one (35\%) were adults and 39 $(65 \%)$ were children under 16 . Sixteen $(27 \%)$ were GP referrals of whom $12(75 \%)$ had received antibiotics. Forty nine $(89 \%)$ saw a doctor within 30 minutes, (mean 16 minutes) and mean time to antibiotics after presenting was 24.8 minutes with $25(71 \%)$ within 30 minutes and $34(97 \%)$ within one hour. Headache, fever, vomiting and rash were the most sensitive features, but occurred in no more than $79 \%$ of patients (lower $95 \%$ confidence interval parameters, see charts). The diagnosis was made/suspected in 45 (75\%) patients. Thirty six $(60 \%)$ were referred to a ward team, $23(38 \%)$ to PICU/ITU, and none discharged with one $(2 \%)$ not recorded. Eight $(29 \%)$ patients sent to a ward ended up on ITU/PICU. Fifty six (94\%) patients were eventually discharged, two (3\%) were transferred and two (3\%) died.

Conclusions-At initial A\&E presentation there are no highly sensitive features to this disease. Formal A\&E protocols based on symptoms/ signs are unfeasible and are no substitute for clinical judgement based on sound teaching. Despite the inconsistency in presentation definitive treatment of identified patients is achievable within 60 minutes of presentation. All such patients need definitive resuscitation and treatment in A\&E. ITU/HDU referral should be considered for all suspected cases. More research from the $\mathrm{A} \& \mathrm{E}$ perspective is needed.

Test lung comparison of the triggering of non-invasive ventilation ventilators under conditions simulating acute exacerbations of chronic obstructive pulmonary disease I M STELL ${ }^{\star}$, G PAUL ${ }^{\star \star}, \mathrm{K} \mathrm{LEE}^{\star \star}$, J PONTE ${ }^{\star \star \star}$, J MOXHAM ${ }^{\star \star \star \star \star}$

${ }^{\star}$ Accident and Emergency Department, Bromley Hospital, Cromwell Avenue, Bromley, Kent BR2 9AF, **Departments of Mechanical Engineering, $\star * \star *$ Anaesthetics and ${ }^{\star * \star}$ Respiratory Medicine, King's College, University of London

There is increasing evidence that the ability of non-invasive ventilation (NIPPV) ventilators to synchronise with the patient's breathing is an important determinant of success with NIPPV; and that the available ventilators vary considerably in this respect. Comparisons between ventilators are conventionally made using "test lungs" to ensure stable test conditions and to avoid the need for invasive monitoring if patients were used. In this collaborative medical/engineering project, a new electronically controlled test lung was developed, able to mimic the tidal flows of acute exacerbations of chronic obstructive airways disease, and in which the physiological factors likely to affect triggering could be independently varied. Thirteen ventilators were tested under a range of conditions selected to be increasingly challenging to ventilator triggering. Condition A: "low" airway resistance $\left(\mathrm{R}_{\mathrm{ww}}\right)\left(3.5 \mathrm{~cm} \mathrm{H}_{2} 0 / 1 / \mathrm{s}\right.$ at 60 1/min), functional residual capacity (FRC) 3.3 litres, $2 \mathrm{~mm}$ leak, tidal volume $\left(\mathrm{V}_{\mathrm{t}}\right) 782 \mathrm{ml}$ condition B: "high" $\mathrm{R}_{\mathrm{w}}\left(20.0 \mathrm{~cm} \mathrm{H} \mathrm{H}_{2} \mathrm{/l} / \mathrm{s}\right.$ at 60 $\mathrm{l} / \mathrm{min}$ ), FRC 3.3 litres, $\mathrm{V}_{\mathrm{t}} 629 \mathrm{ml}$, with three leak sizes: 0, 2 and $4 \mathrm{~mm}$ diameter leaks; and condition C: "high" R, FRC 6.3 litres, and 4 $\mathrm{mm}$ leak, $\mathrm{V}_{\mathrm{t}} 422 \mathrm{ml}$. For each ventilator, under each condition, the test lung was run for one minute, and the mean (ci) (ms) inspiratory and expiratory trigger delay times over 20 breaths were calculated; these being the delays from the onset and end of the test lung inspiration to the appropriate ventilator responses.

Results-The results are shown in table 12 .

Conclusion-(a) NIPPV triggering varies markedly between ventilators, and (b) for most ventilators is poorer under the more challenging conditions that may be encountered in acute exacerbations of chronic obstructive pulmonary disease to an exten that is likely to be clinically important for many of the ventilators tested.

\section{The diagnosis and management of deep} venous thrombosis

C TOVEY, J B HOUGHTON, P A DRISCOLL, I A SAMMY, $D$ W YATES

Accident and Emergency Department, Hope Hospital, Salford M6 $8 H D$

Introduction - The outpatient treatment of deep venous thrombosis (DVT) was initiated in the UK in 1996 by the Haematology and Acciden and Emergency (A\&E) Departments in S Peter's Hospital, Chertsey. The outpatien treatment of DVT is safe and leads to substantial savings in bed costs but many hospitals still do not treat the majority of patients in the community. The aim of this study was to develop evidence-based algorithms for the diagnosis and management of DVT and to evaluate an A\&E consultant based service.

Method-Since November 1999 all patients with possible DVT are seen by an A\&E consultant or registrar. Diagnostic algorithms have been evaluated using selective screening with SimpliRED D-dimer tests and "nea patient" screening with digital photoplephysmography before imaging with ultrasonography or venography. Patients with a confirmed DVT will see a consultant haematologist with responsibility for screening for malignancy and thrombophilia.
Results-Audit has shown that $75 \%$ of such patients will arrive in A\&E between 8 am and $5 \mathrm{pm}(85 \%$ from 8 am to $6 \mathrm{pm})$ on weekdays making a consultant based service easy to achieve. Nearly $50 \%$ of patients arriving in A\&E will be seen within half an hour and 75\% of patients will see an A\&E consultant on the initial visit. More than $40 \%$ of patients undergoing venography or ultrasonography will prove to have a DVT (it is accepted internationally that $25-30 \%$ positive rate is reasonable). In six months there has been only one "missed" DVT. This patient was not suitable for venography and was discharged after a negative ultrasound investigation. She returned two days later with pleuritic chest pain with an intermediate probability of a pulmonary embolus on a VQ scan.

Conclusion-The combination of experienced A\&E staff, SimpliRED D-dimer tests and digital photoplethysmography has resulted in a safe and efficient service with an estimated saving of over 1000 bed days a year, a reduction in the number of investigations performed by radiology and a reduction in the use of low molecular weight heparin. $\mathrm{A} \& \mathrm{E}$ consultants who have considered taking an interest in thromboembolism can gain encouragement from this study.

The use of a SimpliRED D-dimer test in the accident and emergency department C TOVEY, G YOUSSEF, T UNDERHILL

Accident and Emergency Department, Hope Hospital, Salford M6 8HD

Introduction-In recent years there has been an interest in the use of D-dimers to exclude the diagnosis of deep venous thrombosis (DVT). The introduction of a bedside (SimpliRED) D-dimer test allows "near patient" testing in accident and emergency (A\&E). The aim of this study was to evaluate the use of this test when performed by A\&E staff.

Method -63 patients attending the A\&E department with suspected DVT were entered into the study. All patients had blood D-dimer levels measured by A\&E staff using the SimpliRED test before duplex ultrasound.

Results-Three patients with a negative D-dimer test initially had a positive ultrasound scan. In two of these patients a venogram was requested because of the disparity between a positive ultrasound and a negative D-dime test. Both of these venograms confirmed the absence of a DVT. In the third patient a repeat ultrasound by a consultant radiologist confirmed a thrombosis in the superficial short saphenous vein rather than a deep vein. The sensitivity, specificity, negative predictive value and positive predictive value of the SimpliRED D-dimer test were $100 \%, 79 \%, 100 \%$ and $69 \%$ respectively.

Conclusion -Duplex ultrasound is operato dependent and is known to produce false positive results ( $6-8 \%$ of scans). The D-dimer tests for this study cost $f_{169}$ (63 tests at $£^{3}$ each) and detected three false positive results with duplex ultrasound. If it had not been for

Table 12

\begin{tabular}{|c|c|c|c|c|c|c|}
\hline \multirow[b]{2}{*}{ Ventilator } & \multicolumn{2}{|c|}{ Condition A } & \multicolumn{2}{|c|}{ Condition B (4 mm leak) } & \multicolumn{2}{|c|}{ Condition $C$} \\
\hline & Insp delay & Exp delay & Insp delay & Exp delay & Insp delay & Exp delay \\
\hline BiPAP 20 & $86(20)$ & $168(25)$ & $107(14)$ & $128(35)$ & $236(37)$ & $416(46)$ \\
\hline PB 335 & $146(11)$ & $114(7)$ & $169(16)$ & $128(11)$ & $228(11)$ & $182(15)$ \\
\hline VPAP 2 & $240(13)$ & $141(13)$ & $247(4)$ & $161(11)$ & $332(11)$ & $326(11)$ \\
\hline Nippy 2 & $128(11)$ & $\mathrm{n} / \mathrm{a}$ (timed) & $91(14)$ & $\mathrm{n} / \mathrm{a}$ (timed) & $175(11)$ & $\mathrm{n} / \mathrm{a}$ (timed) \\
\hline Rspncs Vision & $86(13)$ & $88(13)$ & $90(13)$ & $99(10)$ & $86(13)$ & $88(15)$ \\
\hline Rspncs PAV & $73(10)$ & $80(8)$ & $88(14)$ & $85(12)$ & $152(16)$ & $76(6)$ \\
\hline
\end{tabular}


this test three patients would have been treated with warfarin for three months with substantial cost to the NHS, inconvenience and anticoagulation risks to the patients. From a clinical and risk management point of view duplex ultrasound should perhaps be combined with a SimpliRED D-dimer test to help prevent false positive results. In this study 34 of the 63 patients with a negative D-dimer test could have been discharged from $A \& E$ without an ultrasound investigation and no DVT would have been missed.

Eliminating barriers to rapid thrombolysis in accident and emergency. Are the targets appropriate and achievable?

A A KHAN, A TAYLOR, C KIRKE, H MCCLELLAND, I BARLOW, W HAMER, T HASSAN

Accident and Emergency Department, The General Infirmary at Leeds, Leeds LS1 3EX

Background - The National Service Framework for Coronary Artery Disease (NSF-CAD) has set tough targets for patients requiring thrombolysis in the accident and emergency (A\&E) department. At present there is little information to confirm the feasibility or reproducibility of using or being able to achieve these standards in a busy A\&E setting.

Objectives-To describe the quality assurance programme for thrombolysis of acute myocardial information (AMI) in our unit, targeting areas for improvement in the process. Secondly, to suggest a more sophisticated, robust, and reproducible model for quality improvement (QI) of patients considered eligible for thrombolysis as compared with that proposed by the NSF-CAD.

Methods - Observational study with targeted feedback of information to clinical staff at regular intervals. Relevant time points from onset of symptoms to interventions in the A\&E department including reported ECG findings were recorded. Data from January 1999 to March 2000 are submitted.

Results-A total of 280 patients were included in the study. Seventeen were excluded because of inadequate data collection. Of the remaining $263,114(43.1 \%)$ were thrombolysed within 30 minutes. Patients who were not thrombolysed within 30 minutes were grouped into separate QI cohorts. Seventy five $(49 \%)$ were deemed to have insufficient initial ECG changes to justify treatment. Seventy four $(51 \%)$ had delayed treatment due to a number of factors including, delay in obtaining an ECG, delay in being seen by a doctor and failure to recognise changes suggestive of AMI. Other groups considered in the QI programme included those that were thrombolysed but showed no evidence of AMI and patients presenting with bundle branch block on their initial ECG.

Conclusions-Significant optimisation of resources will be required to meet the NSFCAD targets for A\&E thrombolysis. A more sophisticated and robust QI programme is suggested which will make comparisons between entries more meaningful.

\section{Children}

Why do children attend accident and emergency with acute asthma?

CLIVE TOVEY, K BAILEY, H CLARKE

Accident and Emergency Department, Hope Hospital, Salford M6 $8 \mathrm{HD}$

Introduction-Children often attend accident and emergency (A\&E) suffering with acute asthma and after treatment with a nebulised bronchodilator the symptoms frequently subside. As bronchodilators should be as effective whether administered via a spacer, a breath actuated inhaler (BAI), a dry powder system or a nebuliser, it may suggest that many children may be using inappropriate medications, no medications at all, an inappropriate drug delivery system or have a poor inhale technique. The aim of this study was to see what children use to treat acute asthma in the community. As children should keep a supply of medications in school an audit at school would provide useful information on what is used to treat acute asthma in the community. Method-76 schools were visited with 19485 pupils aged $4-12$ years.

Results-It is known that 10-15\% of school children suffer with asthma but in this study only $962(4.9 \%)$ of total schoolchildren took bronchodilators to school. In the age group 4-12 years virtually all children should be using a spacer or BAI (for example, Bricanyl Turbohaler, Evans Clickhaler, Ventolin Easibreathe) as most children aged less than 12 would not have the coordination to use an aerosol correctly without a spacer. In this study only $548(2.8 \%)$ children were using spacers or a BAI whereas $414(2.1 \%)$ children were using bronchodilators without spacers. Steroid inhalers should be used twice a day prophylactically (at home). A total of 147 children were found to have steroid inhalers in school presumably to treat acute exacerbations of asthma as many children did not also have a bronchodilator.

Conclusion-Many children are using inappropriate medications or inappropriate devices Although GPs would prescribe spacers many children do not use them as they are quite cumbersome to carry around and children do not like to be seen to be different to their peers. A\&E should encourage the use of BAI and although they are more expensive than aerosols "the most expensive inhaler is the one that does not work"

Characteristics and management of children and adolescents presenting to accident and emergency with deliberate self harm

A NADKARNI, A PARKIN, N DOGRA, D STRETCH, P A EVANS

Greenwood Institute of Child Health, Westcotes House, Westcotes Drive, Leicester LE3 OQU

Objectives - The aim of this study was to study the characteristics and management of children and adolescents presenting to accident and emergency (A\&E) with deliberate self harm.

Method - Descriptive analysis of data collected by reviewing the notes of all children and adolescents aged 16 years and under, presenting during the period of study (1 January to 31 December) with a history of deliberate self harm.

Results - 100 children (18 boys, 82 girls) were responsible for 117 episodes of deliberate self harm. Some $69 \%$ were accompanied by immediate family, while $21 \%$ children had presented alone. Some $49 \%$ presented between $5 \mathrm{pm}$ and midnight. Twenty five per cent had prior or current contact with Child \& Adolescent Mental Health Services (CAMHS). Assessment included investigation of physical complications (88.9\%), reasons for the self harm $(83.8 \%)$, social circumstances $(68.4 \%)$ and previous history of self harm $(54.7 \%)$. After assessment, 72 were discharged from $\mathrm{A} \& \mathrm{E}$ and 36 admitted to paediatric or medical wards. Of those not admitted,
40 were referred to the local CAMHS for further assessment, 24 being seen in the $A \& E$ in the first instance and 26 given a first appointment in the CAMHS outpatient clinic.

Conclusions-Children and adolescents presenting with deliberate self harm to A\&E frequently present alone or are accompanied by people who are not family members making assessment and treatment difficult. The time of presentation is usually out of hours, further complicating this process. Many are already known to CAMHS. Assessment tends to focus on the physical consequences of the attempt. Although guideline produced by the Royal College of Psychiatrists recommend that admission to hospital is desirable, this did not occur in two thirds of the cases. The guidelines also recommend assessment by CAMHS in all cases but this was followed in only one third of cases presenting to $\mathrm{A} \& \mathrm{E}$.

The management of alcohol and drug misuse in children and young peopleSalford Health Action Zone (HAZ) initiative

M MALOBA, I A SAMMY, C TOVEY, D W YATES, J MCKENZIE, T WHITFORD, B LEE, R THOMAS

Accident and Emergency Department, Hope Hospital, Stott Lane, Salford M6 8 HD

Introduction-A report by a joint working party of the Royal College of Physicians and the British Paediatric Association ${ }^{1}$ made the following recommendations: (1) There should be a well defined multi-disciplinary young peoples alcohol and drug service in each district to which referrals can be made. (2) Research into alcohol problems in the young is exceedingly small in relation to the size of the problem. Retrospective audits of intoxicated teenagers has shown that their treatment at accident and emergency (A\&E) departments and their subsequent follow up is inconsistent. Typically such children attend $A \& E$ late at night where they are allowed to sober up before discharge. Most A\&E departments would not routinely screen for drug misuse or carry out a formal psychiatric assessment or arrange follow up.

Method-Funding has been obtained from the HAZ Initiative for a school nurse (HAZ Fellow) who will follow up referrals from A\&E. All young people aged less than 16 (or if in full time education under the age of 19) attending $\mathrm{A} \& \mathrm{E}$ as a consequence of alcohol or drug misuse will be referred to the HAZ Fellow. Links have been established between an alcohol counsellor for the young and the Drug Advisory Service. The HAZ Fellow will refer to these agencies if indicated.

Results-Data being collected include: (1) Extent of problem - we will have data that will provide information on the numbers of patients attending $A \& E$ and the time spent with the HAZ Fellow with each patient. (2) Recurrences-data will be collected about recurrent $\mathrm{A} \& \mathrm{E}$ attendances before and after intervention. (3) School attendance-data will be collected before and after intervention. (4) Preliminary cost analysis. The cost/benefit of screening for drugs and the domino effect on other services will need to be considered. Conclusion - This study is at an early stage and so it is too early to draw conclusions.

1 Anonymous. Alcohol and the young. $\mathcal{F} R$ Coll Physicians Lond 1995;29:470-4. 
Presentation to accident and emergency with crying or screaming and likelihood of child protection registration

A K FLETCHER, D P BURKE

Department of Accident and Emergency, Sheffield Children's Hospital, Western Bank, Sheffield S10 2RX

Aim - To determine whether children aged less than 2 who present to accident and emergency $(\mathrm{A} \& \mathrm{E})$ with crying or screaming as the only complaint, are more likely to be placed on the child protection register in later years than children who do not attend with crying or screaming alone.

Methods-The Sheffield Children's Hospital $A \& E$ database was examined for five years from 1 January 1992. Children were identified who presented at triage with crying or screaming as their sole complaint. Controls were taken from children who presented with any other complaint. Matches were made for sex, postcode and date of birth. All names were checked against files that contained dates of past or present child protection registration. In January 2000, the children's age ranged from 3 to 10 years. The mean follow up period was six years ( $\mathrm{SD}$ one year seven months). Results-From 1 January 1992 until 3 December 1996, 450 children made 462 attendances to $\mathrm{A} \& \mathrm{E}$ with crying or screaming as their only complaint. Of these, 12 had been placed on the child protection register. Ten of the 450 control children had been registered. The odds ratio of subsequent child protection registration if a child presents in Sheffield with crying or screaming alone is 1.21 (95\% confidence intervals 0.52 to 2.82 ).

Discussion - Presentation of young children who cry or scream for no clear reason is relatively common. It has been suggested such children are at risk of abuse. Although child protection registration is not the same as abuse, it is the closest surrogate marker we have. This study shows there is no increased likelihood of child protection registration for children who present with crying or screaming alone and prejudices against parents of these children, if held, are inappropriate.

Children and pain in the neck-should we take them seriously?

A NATARAJAN, D P BURKE, J A FERNANDES, Y G YASSA

Accident and Emergency Department, Paediatric Orthopaedic Department, Sheffield Children's Hospital, Western Bank, Sheffield S10 4TH

It is not uncommon for children to present to the accident and emergency (A\&E) department with neck pain. Minor trauma, viral or upper respiratory infections are the commonest causes. Clinicians managing these children are often inclined to treat them as torticollis with analgesics and reassure their parents that these are self limiting ailments.

Less common but more sinister underlying causes may present as neck pain in childhood. The aim of this paper is to draw attention to these unusual conditions masquerading as neck pain and to emphasise the need for early recognition of such conditions.

We describe a series of five patients who presented with pain in the neck to our $A \& E$ department over a period of 12 months. Our department serves 34000 new patients a year. The cases we report emphasise that the presence of neck pain especially if persistent and associated with abnormal neck posturing or gait abnormalities should act as a possible indicator of other less common but potentially more sinister diagnoses such as posterior fossa tumour, eosinophilic granuloma or discitis. Appropriate evaluation of such cases is discussed.

\section{Children and magnets-an almost fata} attraction

SIMON MCCORMICK, P O B BRENNAN, R N SHAWAS, JANET G YASSA

Accident and Emergency Department, Paediatric Surgical Department, Sheffield Children's Hospital, Western Bank, Sheffield S10 4TH

Children imitating adults often seem to indulge in harmless fun, however at times these activities have more serious implications. The recent fashion of body piercing among adults has encouraged children to have similar procedures or imitate them by applying small magnets to sustain the jewellery used in piercing in position.

We present a series of 24 cases presented to the Sheffield Children's Hospital over a period of eight weeks. The children imitated body piercing by using small powerful magnets across parts of their body including nose, ears, penis and tongue. Some swallowed the magnet while attempting to use them.

Several of them have had complications, including one who had near fatal surgical complications.

We describe the details of the patients, the procedures used to detect the magnets and the management of the different complications encountered.

\section{The accident and emergency process}

Should ambulant patients be directed to reception or triage first?

STEVE GOODACRE, FRANCIS MORRIS, BINIAM TESFAYOHANNES, GARETH SUTTON

Accident and Emergency Department, Northern General Hospital, Herries Road, Sheffield S5 $7 A U$

Objectives-Developments in triage have lead to patients being directed to triage rather than reception upon arrival in accident and emergency (A\&E). We aimed to determine whether attending triage or reception first, was preferable in terms of timeliness, clarity and safety. Methods-We compared two consecutive four week periods during which patients were directed to attend triage first and then reception first. Observers recorded their actions on arrival. Questionnaires recorded the patients' perceptions of each strategy. High priority triage categories were audited during the reception first phase.

Results - 1850 patients were observed in the triage first phase with a mean door to triage time of 10.6 minutes, triage to reception 5.3 minutes and door to reception 15.8 minutes. Altogether 1522 patients were observed in the reception first phase with a mean door to reception time of 0.5 minutes, reception to triage 12.4 minutes and door to triage of 12.9 minutes. Patients were more likely to presen to the appropriate place during the reception first phase $(88 \% v 34 \%)$ and reported shorter waiting times and better understanding of instructions. No case given triage category one or two suffered an adverse outcome resulting from delay associated with attending reception first.

Conclusion-Directing patients to attend reception first is timely and less confusing. It is safe provided booking in does not delay assessment by more than 15 minutes.
The changing management of acute medical patients

N CONTRACTOR, I SAMMY

Accident and Emergency Department, Hope Hospital, Stott Lane, Salford M6 8HD

Introduction-Emergency medical admissions in Britain are rising. A report by the Councils of International Hospitals in 1996 recommended the development of acute assessment units. Some of the recommendations in the Royal College of Physicians Working Party report include appointment of a doctor who has overall management of the unit or a weekly consultant in charge, and twice daily consultant ward rounds.

Objectives-To assess if medical assessment units that are already established meet the recommendations of the report in 1996 and the new report from the Royal College of Physicians.

Method - A list of all hospitals with a CCU and/or ITU in Britain was composed from the directory of emergency and special care units. It was assumed these hospitals would be treating acute medical patients. The questionnaire was composed of 13 questions and then requested general comments.

Results-So far, $40.5 \%$ of units have a named doctor in charge of the unit, and the majority of these doctors are from internal medicine. Although, some units are managed by accident and emergency and ITU doctors. Of the remaining units, only $10.4 \%$ of these rotate through a consultant in charge for the week. Some $5.8 \%$ of units have no consultant ward rounds, $42 \%$ have one ward round and $50.7 \%$ have two.

Conclusions - Many hospitals have already developed medical assessment units. The main area of deficiency regards medical staff. The majority of departments do not have a docto in overall charge of the unit. This is likely to have adverse effects in both efficiency and risk management. Also, many departments do not have additional staff to on call doctors. Medical assessment units are still in the early stages of development, and as more research is done, continued improvements can be made.

Out of hospital cardiac arrest-factors affecting survival. A 3.5 year prospective observational study at Glasgow Royal Infirmary

FRANK WESTERDUIN, RUDY CRAWFORD

Accident and Emergency Department, Glasgow Roya Infirmary, 84 Castle Street, Glasgow G4 $O S F$

A prospective observational study of all cardiac arrests brought to Glasgow Royal Infirmary Accident and Emergency (A\&E) department over a 3.5 year period (November 1996 to May 2000).

Approximately 600 cardiac arrests with an underlying cardiac cause were managed ove this period. Specific features were examined. $\mathrm{VF}$ was the presenting rhythm in $46 \%$. Overall survival to discharge from hospital was $5.5 \%$. There were no survivors to hospital discharge who had not had a return of spontaneous circulation prior to arrival at hospital. There was no improvement in survival in arrests treated by paramedics as compared with technician crews. The majority of arrests $(50 \%)$ occurred in the home. The majority of arrests $(75 \%)$ were witnessed and bystander CPR was performed in half of these. There were four survivors out of seven arrests (57\%) occurring at a football ground with onsite first aiders equipped with automated external defibrillators, ambulance crews and medical cover. 
This represents $12.5 \%$ of the total survivors to discharge from hospital. The pre-hospital times in relation to survival were examined.

In addition to continuing to highlight the importance of urgent action by the public, steps need to be taken to reduce the delay to defibrillation. Early defibrillation has been shown to improve survival in cardiac arrest. Studies show that the best survival rates are achieved in two or three tiered EMS response systems compared with a single response as currently exists in the UK. The involvement of the police, fire brigade and where appropriate the voluntary ambulance service as first responders equipped with automated external defibrillators in Britain would be a major step forward in improving our survival rates in cardiac arrest.

Does live television football affect attendances at accident and emergency departments

S H BOYCE

Crosshouse Hospital, Kilmarnock

Aim - To determine if live terrestrial television football broadcasts affect patient attendance at an accident and emergency (A\&E) department.

Method-Glasgow Rangers football club, the Scottish league champions, were competing in the European Champions League season $1999 / 2000$. The competition was played for six weeks, either on a Tuesday or Wednesday evening. The matches were broadcast live on Scottish television, the programme commencing at 1930 and ending at 2200. Patients attending the A\&E department during these hours on each match night were noted prospectively. Only self presenting patients were noted. All specialty receiving patients were excluded. The patients attending on all other week nights during these hours were noted and a weekly average figure calculated. Results-Attendance was reduced on four of the six match nights. The reduction was most marked on the night of the first and last game, both deemed to be crucial matches, with attendance being $63 \%$ and $51 \%$ respectively of the weekly average.

Conclusion-The results demonstrate that there is an apparent decrease in patient attendance during match nights, although not exclusively. Other factors, for example, weather, time of year, also require consideration.

A retrospective study on ENT presentation and its appropriateness of management in accident and emergency departments

M DE, A ANDE

Crosshouse Hospital, Accident and Emergency Department, Kilmarnock KA2 OBE

Objectives-To determine the management by accident and emergency (A\&E) staff of patients attending an A\&E department with ENT problems and to identify problems with patient management or patient disposal.

Method - This is a retrospective analysis of the patients presenting with ENT problems to $\mathrm{A} \& \mathrm{E}$ department. One hundred patients were randomly selected from patients attending over a six month period. They were assessed on time of attendance, mode of presentation, management and appropriateness of such management.

Result-The ages of patients seen ranged from $2-94$ years. The vast majority $(86 \%)$ of attendances were between the hours of 9 am and midnight. The commonest presenting symptom was a nose bleed (26\%). Some form of treatment was carried out in $68 \%$ of al cases. No treatment was required in $32 \%$ of the cases, where the problem had resolved or where no significant problem was detected. The use of other hospital resources (that is, radiology and other laboratory services) was uncommon and referral to ENT department occurred in less half the patients $(44 \%)$. Review of the casenotes suggested that the management was entirely appropriate in $86 \%$. Conclusion - This study reveals that the majority of the patients were managed satisfactorily with appropriate follow up. It could be argued however, that in view of the infrequent use of acute hospital resources that a significant number of these patients could be treated by their own GPs, thereby reducing the workload on hospital A\&E departments.

\section{$\underline{\text { Trauma (2) }}$}

The flow of patients following a major incident, the Omagh bomb

MARK G JENKINS, ALAN MCKINNEY

Ulster Hospital, Belfast

Aim-To chart the flow of the patients involved in the Omagh bomb as they were transferred around the hospitals of Northern Ireland for ongoing and definitive care.

Methods-All hospital attendances following the Omagh bomb were identified. The flow of patients transferred from the Tyrone County Hospital were traced using their original notes and notes from their subsequent hospital admissions.

Results-Three hundred and nine patients made immediate contact with the Health Services following the Omagh bomb. Seven hospitals were involved in the immediate and aftercare of the patients involved in the bomb. Flow charts will be used to illustrate the immediate transfers (first 24 hours), secondary transfers ( $2-3$ days) and tertiary referrals. Conclusion - In this major incident, the initial receiving hospital was inundated. The bomb scene was clear of living casualties within 20 minutes. Due to this and The Tyrone County Hospital's geographical isolation, a triage system was used. Patients were referred on to neighbouring, area and regional tertiary care centres appropriately for continuing and definitive care.

Revised trauma scores and mode of transfer of patients after a major incident, the Omagh bomb

MARK G JENKINS, ALAN MCKINNEY

Ulster Hospital, Belfast

Aim - To correlate revised trauma score of patients involved in the Omagh bomb and their subsequent method of transfer.

Method-All patients involved in the Omagh bomb transferred from the Tyrone County Hospital for further/ongoing treatment were identified. From their notes pulse, blood pressure, respiratory rate and Glasgow coma scale were recorded. These same parameters were noted before and after transfer. Mode of transfer was also recorded. Their subsequent revised trauma score was calculated.

Results - Three hundred and nine patient made immediate contact with the hospital services after the explosion. Sixty seven patients required transfer to area and regional hospitals. Forty two went by ambulance, 6 by car and 19 by helicopter (table 13). Two patients had deterioration in their revised
Table 13

\begin{tabular}{llll}
$\begin{array}{l}\text { Revised } \\
\text { trauma score }\end{array}$ & Car & Ambulance & Helicopter \\
\hline 5 & 0 & 0 & 1 \\
6 & 0 & 2 & 1 \\
7 & 0 & 2 & 0 \\
8 & 6 & 38 & 17 \\
\hline
\end{tabular}

trauma score after transfer by helicopter. These will be discussed.

Conclusion - In a major incident, there seems to be a group of patients that "self triage", they know they are well enough to transfer themselves. Helicopters transfer patients quickly but there is a risk of deterioration.

Injury severity scores and mode of transfer of patients after a major incident, the Omagh bomb

MARK J JENKINS, ALAN MCKINNEY

Ulster Hospital, Belfast

Aim-To correlate injury severity scores of patients involved in the Omagh bomb and their subsequent method of transfer.

Method-All patients involved in the Omagh bomb transferred from one of the Tyrone County hospital for further/ongoing treatment were identified. Injuries were recorded from their notes. Anatomical injury scores and subsequent injury severity scores (ISS) were calculated. The mode of transfer from the hospitals to area and regional centres were identified from notes and Northern Ireland Ambulance Service records.

Results-Three hundred and nine patients made immediate contact with the hospital services after the explosion. Sixty seven patients required transfer to area and regiona hospitals. Forty two went by ambulance, 6 by car and 19 by helicopter. The patients within the car group, self triaged and only one of this group was seriously injured with an ISS of 14 (range 1-14, median 3). Ambulance patients had an ISS range of 1-34 and helicopter patients had an ISS range of 6-75. An ISS of $>16$ indicates serious trauma, 9 helicopter patients and 11 ambulance patients had these scores.

Conclusion-Helicopter transfer for the geographical isolation was an ideal method of transfer for the patients from the Omagh bomb and staff from Tyrone County hospital tried to do this. Such transfer is hampered by problems of staff availability to transfer patients and a desire to fill available space in the helicopters even if this meant sending less seriously injured to make up the numbers.

Deaths among car drivers and their passengers

M PARRIS, J P WYATT, D BEARD, A BUSUTTIL Forensic Medicine Unit, University of Edinburgh, Scottish Trauma Audit Group and Accident and Emergency Department, Royal Infirmary, Lauriston Place, Edinburgh EH3 9YW

Deaths among car drivers and their passengers in Lothian and Border regions of south east Scotland between 1994 and 1998 were identified in a prospective study involving collaboration between Forensic Medicine, Scottish Trauma Audit Group and accident and emergency (A\&E). The circumstances surrounding each death were examined using police reports held by the Procurator Fiscal. Ambulance and hospital records provided information about the treatment provided and time of death. Detailed necropsies were performed using a standardised 
fashion from which a list of all the injuries sustained was prepared, enabling them to be scored using the Abbreviated Injury Scale (1990 revision).

One hundred and fifty nine deaths $(122$ male, 37 female) occurred during the five year period. Various forms of "human error" were implicated in causing the majority of deaths, which included combinations of the following: excessively fast driving, driving under the influence of alcohol, attempting dangerous overtaking manoeuvres and failure to wear an available seat belt. Most of those who died were found dead at scene. There were 72 people with unsurvivable injuries (AIS $=6$, Injury Severity Score $=75$ ) causing immediate death at scene, which mainly involved injury to the brain, brainstem, thoracic aorta and upper spinal cord.

The results of this study confirm the continuing role of road traffic collisions in causing premature death in south east Scotland. The predominance of prehospital deaths and the frequency of unsurvivable injury underlines the importance of injury prevention measures in the future prevention of such deaths. Given the background to many of the collisions it is clear that efforts need to be aimed at changing the behaviour of both car drivers and their passengers.

Intravenous fluid use in accident and emergency departments: effects of published studies in medical literature

E C CROWHURST, N O'CONNOR, P A EVANS

Accident and Emergency Department, Leicester Royal Infirmary NHS Trust, Leicester LE1 5WW

Background and methods - In view of the continuing controversy over the safety of colloids and albumin since the meta-analyses published in the British Medical Fournal in 1998 we sought to assess prescribing practice by means of postal questionnaires. These were sent to all accident and emergency (A\&E) consultants (459) in the UK and Republic of Ireland around the time of the first metaanalysis with a follow up in 1999. Similar questionnaires were then sent to all consult-

Table 14

\begin{tabular}{lllllll}
\hline & ADP & Collagen & Adrenaline & Ristocetin & $\mathrm{Ca}^{2+}$ & $\mathrm{Mg}^{2+}$ \\
\hline Whole blood & $58(9)$ & $91(1)$ & $38(5)$ & $28(9)$ & 1.16 & 0.46 \\
Plasma & $55(9)$ & $57(12)^{\star}$ & $19(3)^{\star}$ & $13(5)$ & 1.16 & 0.50 \\
Saline & $69(4)+$ & $80(7)$ & $35(6)+$ & $65(11)+$ & $0.77+$ & $0.30+$ \\
Haemaccel & $32(7)+$ & $42(11)$ & $11(2)+$ & $-8(3)+$ & $2.88+$ & $0.36+$ \\
Gelofusine & $82(3)+$ & $88(2)+$ & $45(8)+$ & $4(3)$ & $0.70+$ & $0.28+$ \\
Albumin & $70(4)+$ & $74(5)$ & $26(5)+$ & $38(11)+$ & $0.67+$ & $0.26+$ \\
\hline
\end{tabular}

${ }^{*} \mathrm{p}<0.05$ cf whole blood. $+\mathrm{p}<0.05$ cf dilution with autologous plasma.

ants in burns units (205) and intensive rherapy units (ITUs) (1444). In the A\&E survey consultants chose the one fluid they would use: for burns and ITU, they ranked fluids ( 1 =first choice, etc).

Results-Overall response rates: $88 \%$ initial and $64 \%$ follow up A\&E surveys, 55\% burns and ITU surveys. For trauma: A\&E consultants preferred crystalloids: Ringer's lactate ( $46 \%$ adults, $43 \%$ children), norma saline (25\% adults, $23 \%$ children). In ITUs the first choice was Gelofusine (mean rank 4.6) in adults and normal saline (4.5) in children. For burns: In adults: $\mathrm{A} \& \mathrm{E}$ consultants preferred crystalloids: Ringer's lactate (37\%), normal saline (25\%). For children and all ages at the burns unit: albumin is the preferred fluid $(34 \%$ for children at $\mathrm{A} \& \mathrm{E}$ rank orders 4.0 adult, 4.5 children at burns unit).

Conclusions - Since the meta-analyses consultants have changed their practice. Those who have stopped using colloids: in $\mathrm{A} \& \mathrm{E}$ for trauma: $11 \%$ adults, $13 \%$ children. In ITU practice: $1.5 \%$ adults and $1.7 \%$ children. For burns in A\&E: $13 \%$ adults, $14 \%$ children. At burns units: $7 \%$ changed their practice in view of the colloid meta-analysis. Those who have stopped using albumin: in A\&E for trauma: $1.7 \%$ adults, $7.2 \%$ children. In ITU practice: $31 \%$ adults, $18 \%$ children. For burns in A\&E $12 \%$ adults, $16 \%$ children. At burns units: $14 \%$ changed their practice in view of the albumin meta-analysis. Thus the published meta-analyses have had a marked impact on intravenous fluid use resulting in a significan reduction in the use of these fluids in clinical practice.
Studies on the effects of resuscitation fluids on platelet aggregation in vitro E C CROWHURST, J GLENN, S HEPTINSTALL, P A EVANS

Accident and Emergency Department, Leicester Royal Infirmary NHS Trust, Leicester LE1 5WW

Continuing controversy exists over fluids used for trauma and burns and their haemostatic effects. In this study, effects on platelet aggregation were determined in whole blood and compared with results obtained after diluting blood with autologous plasma. This acted as a non-crystalloid, non-synthetic colloid control.

The fluids or plasma were added to hirudinised whole blood from volunteers $(n=10)$ in the ratio 2:3 (to model the ATLS protocol). Aggregation was measured in response to ADP collagen, adrenaline and ristocetin. Results were compared with those for undiluted blood and expressed as mean (SEM) percentage aggregation. Ionised $\mathrm{Mg}^{2+}$ and $\mathrm{Ca}^{2+}$ were measured using an AVL Analyser (table 14).

Reducing the cell count by adding autologous plasma to whole blood, reduced aggregation in response to collagen and adrenaline, but not ADP. Saline and Gelofusine enhanced aggregation in response to $\mathrm{ADP}$, collagen and adrenaline, possibly as a consequence of lowered $\mathrm{Ca}^{2+}$. Haemaccel always inhibited aggregation further, probably through increased $\mathrm{Ca}^{2+}$ and, like Gelofusine, abolished ristocetin induced responses. Compared with saline and Gelofusine, albumin usually limited enhancement of aggregation consequent to creating a low $\mathrm{Ca}^{2+}$ environment. Therefore we anticipate that the effects of these fluids in clinical practice will depend largely on the extent of changes in blood cell counts and the rapidity with which homeostatic mechanisms correct accompanying changes in plasma $\mathrm{Ca}^{2+}$. 